\title{
Valproate-associated Movement Disorder: A Literature Review
}

\author{
Jamir Pitton Rissardo ${ }^{1}$, Ana Letícia Fornari Caprara ${ }^{1}$, Ícaro Durante ${ }^{2}$ \\ ${ }^{1}$ Department of Medicine, Federal University of Santa Maria, Santa Maria, Brazil; \\ ${ }^{2}$ Department of Medicine, Federal University of Fronteira Sul, Passo Fundo, Brazil
}

Received February 21, 2020; Accepted August 22, 2021.

Key words: Valproate - Valproic acid - Review - Movement disorder - Druginduced

\begin{abstract}
Valproate (VPA) was first synthesized in 1882, but it was only in the early 1960 s that its anticonvulsant properties were discovered. The aim of this literature review is to evaluate the clinical epidemiological profile, pathological mechanisms, and management of VPA-associated movement disorder (MD). Relevant reports in six databases were identified and assessed by two reviewers without language restriction. A total of 138 reports containing 362 cases of subjects who developed a MD secondary to VPA were reported. The MD identified were parkinsonism (PKN) (252), myoclonus (MCL) (54), dystonia (DTN) (17), dyskinesia (DKN) (16), stutters (4), tics (3), akathisia (AKT) (1). In the not clearly defined group, 15 extrapyramidal symptoms, 3 AKT, 2 DTN, 1 rigidity, 1 unstable gait were assessed. The mean and median age was 55.8 (SD: 16.58) and 61 years (range: 4-87 years). The most common VPA-indication was epilepsy, and $51.36 \%$ were males. The mean and median time from the VPA start to the MD onset was 32.75 (SD: 30.05) and 21.15 months (range: 1 day - 20 years). The mean and median time from the VPA withdrawal until the MD recovery was 2.89 (SD: 2.79) and 3 months (1 day 12 months). The most common management was drug withdrawal. A complete recovery was obtained in $80.61 \%$. VPA-associated MD was extensively reported in the literature. PKN was the most well-described. Future studies need to clearly report the clinical history of the patient, considering the full investigation of other adverse events during their entire life.
\end{abstract}

Mailing Address: Dr. Jamir Pitton Rissardo, Av. Roraima, 1000 - Camobi, Santa Maria - RS, 97105-900, Brazil; Phone: (55) (55) 334729 08;

e-mail: jamirrissardo@gmail.com 


\section{Introduction}

Valproate (VPA), and its pharmacological forms such as valproic acid, sodium valproate, and valproate semisodium are anticonvulsants (Figure 1). In 1882, Beverly Burton synthesized VPA for the first time; this compound was used for almost eighty years as an inert solvent in laboratories (Lempérière, 2001). Pierre Eymard, in the early 1960s, during animal studies to develop a new antiepileptic drug, noted that the substances dissolved in VPA had apparently better anticonvulsant properties (Henry, 2003). After this observation, many clinical studies showed the efficacy and safety of VPA for the management of focal seizures (Brugger et al., 2016). In 1967, it was approved as an antiepileptic drug in France (Henry, 2003). Only in 1983, the Food and Drug Administration approved this medication for the treatment of epilepsy (Lempérière, 2001). The first study assessing the efficacy of VPA in bipolar disorder was done by Lambert et al. at the end of the 1960s in France, soon after the approval for epilepsy, which showed good results, but for many years these data were believed to be incidental, due to the small number of subjects studied (Henry, 2003). About ten years later, German clinical trials followed by North American studies supported the hypothesis of Lambert et al. In 1995, VPA was approved as monotherapy during manic episodes by the FDA (Lempérière, 2001).

The mechanism of action of VPA is not completely understood (Figure 2) (Lempérière, 2001; Löscher, 2002; Bowden, 2003; Henry, 2003; Brugger et al., 2016). Its main interactions are related to the voltage-gated sodium channels blockage and increased brain levels of gamma-aminobutyric acid (GABA) (Löscher, 2002). The increased concentration of this neurotransmitter is believed to occur due to indirect inhibition of the GABA's reuptake and degradative enzymes. Also, it is worth mentioning that this GABAergic mechanism probably explains the anticonvulsant and antimanic properties of this drug (Bowden, 2003). Other pathways that VPA is related include the Kv7.2, AKAP5, and histone deacetylase (Löscher, 2002). It is hypothesized that the inhibition of the histone deacetylase may have neuroprotective effects due to the increased uncoiling of DNA promoting more transcriptional activity of chromatin structures (Bowden, 2003).

The adverse effects of this medication that affect more than ten percent of users are nausea, vomiting, headache, coagulation disorders (Rissardo et al.,

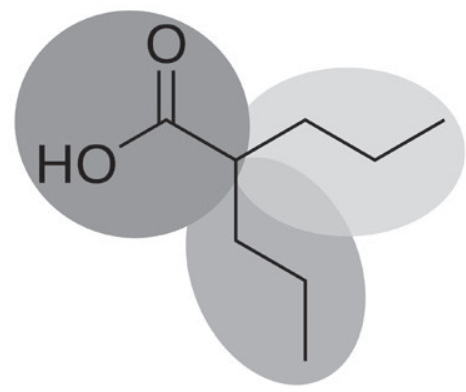

Figure 1 - Skeletal formula of the anticonvulsant drug valproic acid, also known as 2-propylvaleric acid. 


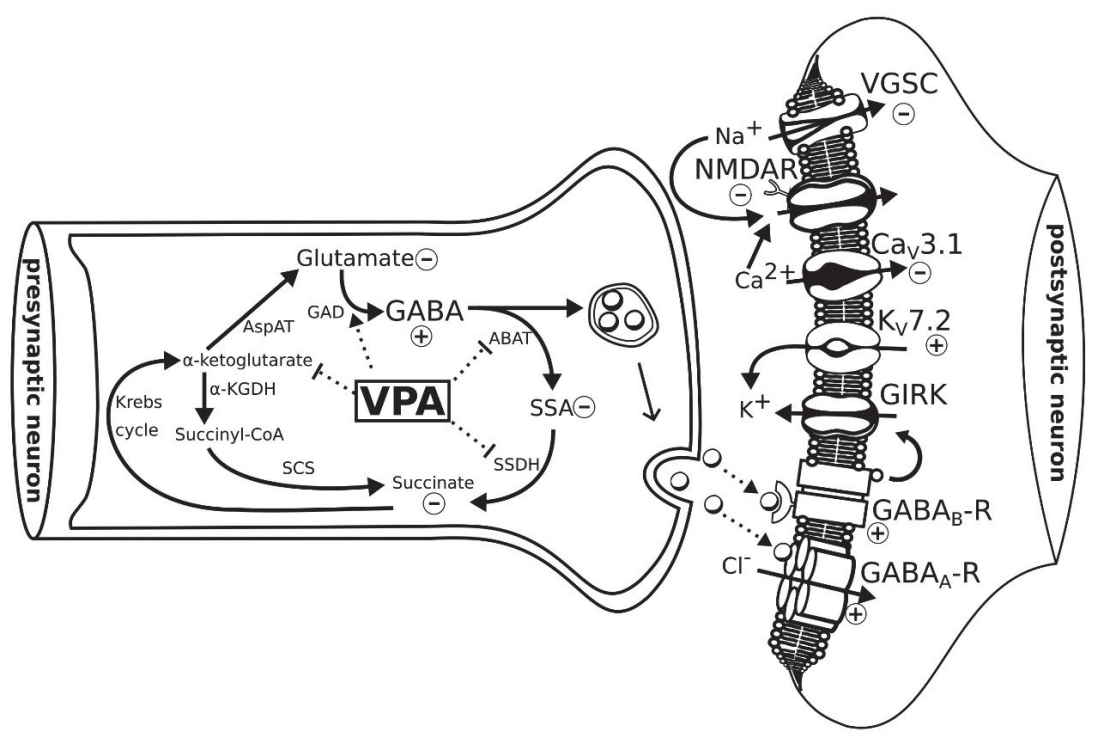

Figure 2 - Representation of proposed mechanisms of action for valproate (VPA). $\alpha-K G D H$ - alpha-ketoglutarate dehydrogenase; ABAT - 4-aminobutyrate aminotransferase; AspAT - aspartate aminotransferase; CaV3.1 voltage-gated calcium channel; GABA - gamma-aminobutyric acid; GABAA/B- $R$ - GABAA/B receptor; GAD glutamate decarboxylase; GIRK - G protein-gated inwardly rectifying potassium channel; KV7.2 - voltage-gated potassium channel; NMDAR - N-methyl-D-aspartate receptor; SCS - succinyl CoA synthetase; SSA - succinic semialdehyde; SSDH - succinate-semialdehyde dehydrogenase; VGSC - voltage-gated sodium channel.

2019), alopecia, asthenia, somnolence, amblyopia, diarrhea, dizziness, dyspepsia, nystagmus, and tinnitus (Bowden, 2003). In the label of VPA, there is a black box warning about hepatotoxicity in susceptible individuals (those with mitochondrial diseases), teratogenicity, and pancreatitis (Löscher, 2002). Other common side effects secondary to VPA are movement disorders (MD) such as tremor and ataxia, which can significantly impact the quality of life of an important percentage of the VPA users. Moreover, these abnormal movements are challenging to diagnose and manage in the clinical practice, because the majority of affected individuals have a pre-existing psychiatric or neurologic comorbidity.

In the literature, there are few reviews about VPA and MD that were not focused solely on tremors. To be more specific, we found two reviews about VPA-induced parkinsonism (PKN). Mahmoud and Tampi published a study about this topic in 2011; they objectively selected elderly patients, and a total of thirteen case reports were analysed. In 2016, Brugger et al. searched on four databases for papers in English about VPA and PKN, a total of 116 patients were evaluated; their purpose was to discuss the possible hypotheses for these adverse effects. In this context, the aim of the present literature review is to evaluate the clinic-epidemiological profile, pathological mechanisms, and management of VPA-associated MD. 


\section{Methods}

Search strategy

We searched six databases and also abstracts of the "International Congress of the Parkinson's Disease and Movement Disorders (1990-2019)" in an attempt to locate any and all existing reports on movement disorders (MD) secondary to VPA published between 1975 and 2019 in electronic form. Excerpta Medica (Embase), Google Scholar, Latin American and Caribbean Health Sciences Literature (Lilacs), Medline, Scientific Electronic Library Online (Scielo), and ScienceDirect were searched. Search terms were "parkinsonism, dyskinesia, dystonia, stuttering, myoclonus, restless legs syndrome, akathisia, tremor, chorea, tics, restlessness, ataxia, ballism, hyperkinetic, hypokinetic, bradykinesia, movement disorder". These terms were combined with "valproate, valproic acid" (Table 1).

\section{Inclusion and exclusion criteria}

Case reports, case series, original articles, letters to the editor, bulletins, and poster presentations published from 1975 to 2019 were included in this review with no language restriction. The authors independently screened the titles and abstracts

\section{Table 1 - FreeText and MeSH search terms in the US National Library of Medicine}

\begin{tabular}{|c|c|c|}
\hline Category & Search terms & Results \\
\hline Parkinsonism & 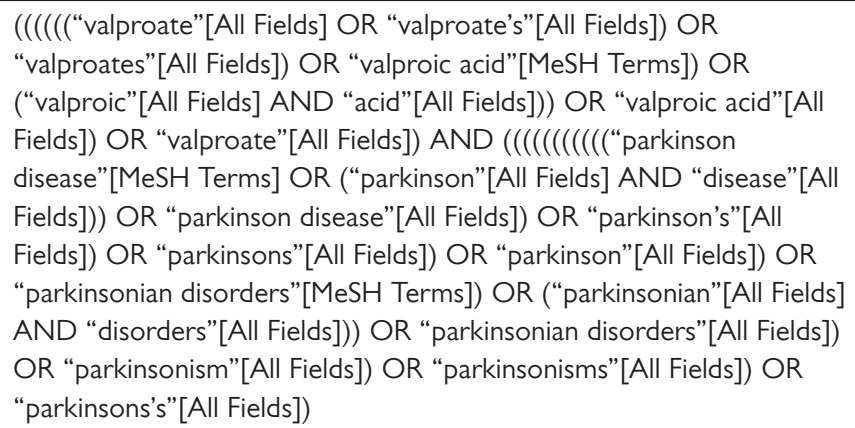 & 180 \\
\hline Tics & 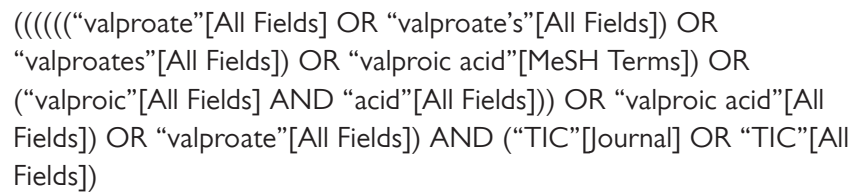 & 15 \\
\hline Dyskinesia & $\begin{array}{l}\text { (((((“valproate”[All Fields] OR “valproate's”[All Fields]) OR } \\
\text { "valproates”[All Fields]) OR “valproic acid”[MeSH Terms]) OR } \\
\text { (“valproic”[All Fields] AND “acid”[All Fields])) OR “valproic acid”[All } \\
\text { Fields]) OR “valproate”[All Fields]) AND ((((“dyskinesiae”[All Fields] } \\
\text { OR “dyskinesias”[MeSH Terms]) OR “dyskinesias”[All Fields]) OR } \\
\text { "dyskinesia”[All Fields]) OR “dyskinesis”[All Fields]) }\end{array}$ & 576 \\
\hline
\end{tabular}




\begin{tabular}{|c|c|c|}
\hline Category & Search terms & Results \\
\hline Dystonia & 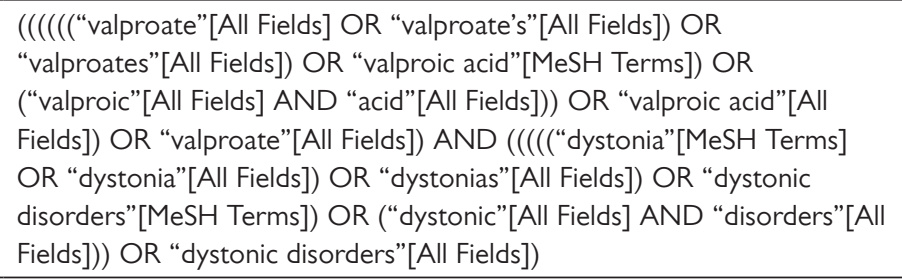 & 54 \\
\hline Stuttering & 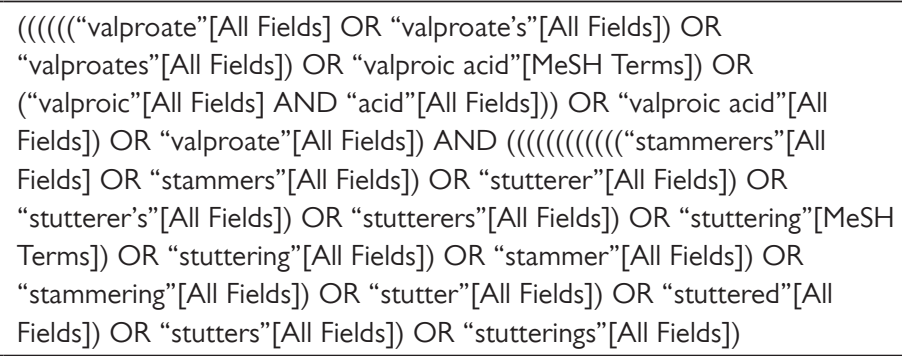 & 10 \\
\hline Myoclonus & $\begin{array}{l}\text { (((((“valproate”[All Fields] OR “valproate's”[All Fields]) OR } \\
\text { "valproates”[All Fields]) OR “valproic acid”[MeSH Terms]) OR } \\
\text { (“valproic”[All Fields] AND "acid”[All Fields])) OR “valproic acid”[All } \\
\text { Fields]) OR “valproate"[All Fields]) AND ((("myoclonias”[All Fields] } \\
\text { OR “myoclonus”[MeSH Terms]) OR “myoclonus”[All Fields]) OR } \\
\text { "myoclonia”[All Fields]) }\end{array}$ & 345 \\
\hline $\begin{array}{l}\text { Restless legs } \\
\text { syndrome }\end{array}$ & 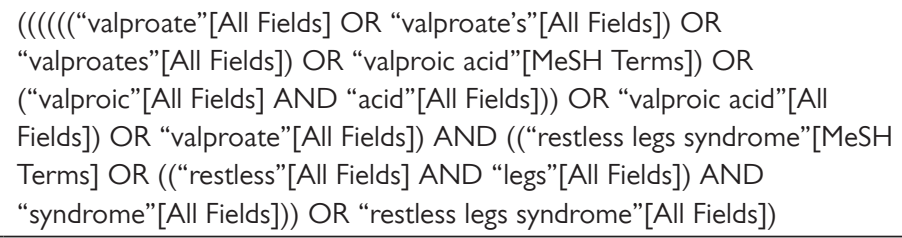 & 17 \\
\hline Akathisia & 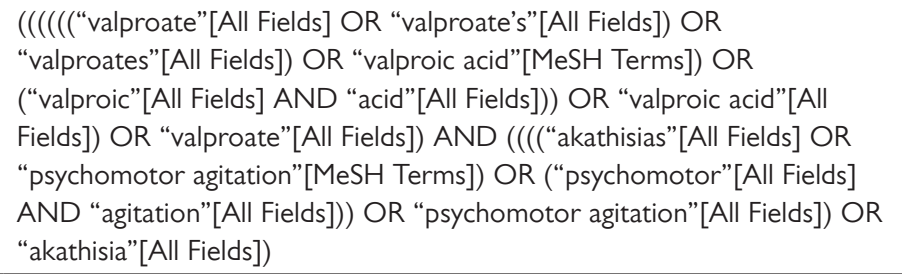 & 122 \\
\hline Tremor & 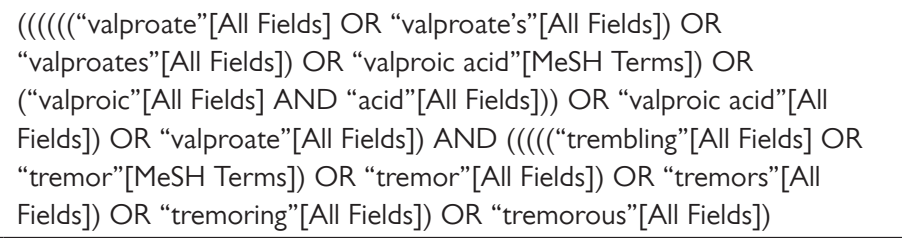 & 222 \\
\hline Chorea & 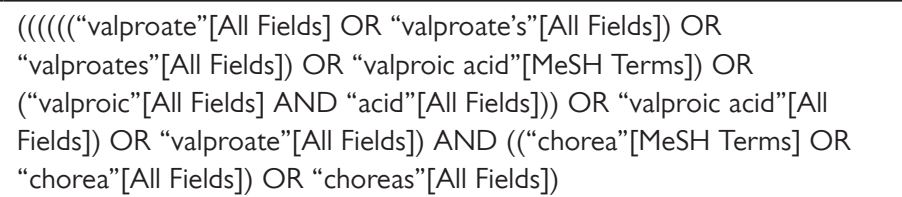 & 124 \\
\hline
\end{tabular}

Rissardo J. P.; Caprara A. L. F.; Durante Í. 


\begin{tabular}{|c|c|c|}
\hline Category & Search terms & Results \\
\hline Restlessness & 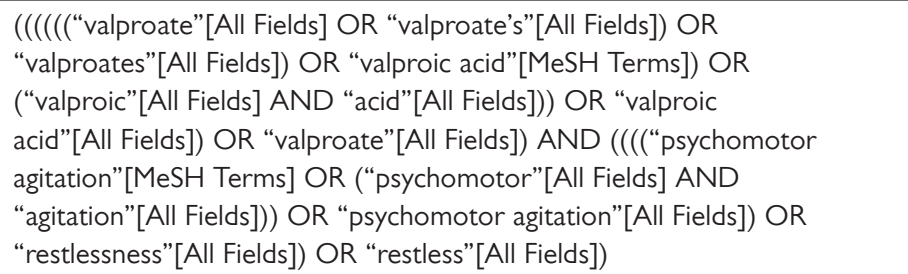 & 124 \\
\hline Ataxia & $\begin{array}{l}(((((\text { “valproate”[All Fields] OR “valproate's”[All Fields]) OR } \\
\text { "valproates”[All Fields]) OR “valproic acid”[MeSH Terms]) OR } \\
\text { (“valproic”[All Fields] AND “acid”[All Fields])) OR “valproic acid”[All } \\
\text { Fields]) OR “valproate"[All Fields]) AND ((“ataxia”[MeSH Terms] OR } \\
\text { "ataxia"[All Fields]) OR "ataxias”[All Fields]) }\end{array}$ & 205 \\
\hline Ballism & $\begin{array}{l}\text { ((((((“valproate”[All Fields] OR “valproate's”[All Fields] }) \text { OR } \\
\text { "valproates”[All Fields]) OR “valproic acid”[MeSH Terms]) OR } \\
\text { (“valproic”[All Fields] AND “acid”[All Fields])) OR “valproic acid”[All } \\
\text { Fields]) OR “valproate"[All Fields]) AND ((“dyskinesias”[MeSH Terms] OR } \\
\text { "dyskinesias"[All Fields]) OR “ballism”[All Fields]) }\end{array}$ & 542 \\
\hline Hyperkinetic & $\begin{array}{l}(((((\text { “valproate”[All Fields] OR “valproate's”[All Fields]) OR } \\
\text { "valproates”[All Fields]) OR “valproic acid”[MeSH Terms]) OR } \\
\text { (“valproic”[All Fields] AND “acid”[All Fields])) OR “valproic acid”[All } \\
\text { Fields]) OR "valproate”[All Fields]) AND (“hyperkinetic”[All Fields] OR } \\
\text { "hyperkinetics”[All Fields]) }\end{array}$ & 20 \\
\hline Hypokinetic & $\begin{array}{l}(((((\text { “valproate”[All Fields] OR “valproate's”[All Fields]) OR } \\
\text { “valproates”[All Fields]) OR “valproic acid”[MeSH Terms]) OR } \\
\text { (“valproic”[All Fields] AND "acid”[All Fields])) OR “valproic acid”[All } \\
\text { Fields]) OR “valproate”[All Fields]) AND ((“hypokinesia”[MeSH Terms] } \\
\text { OR “hypokinesia”[All Fields]) OR "hypokinetic”[All Fields]) }\end{array}$ & 9 \\
\hline Bradykinesia & 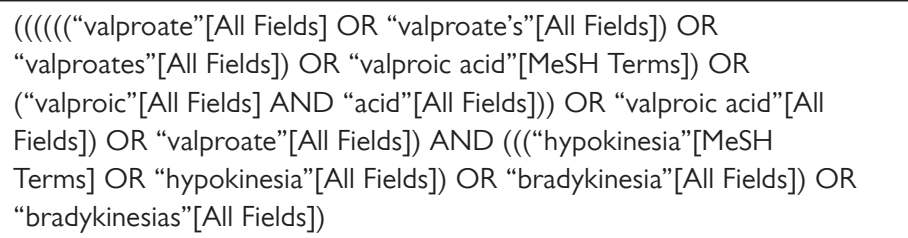 & 12 \\
\hline $\begin{array}{l}\text { Movement } \\
\text { disorder }\end{array}$ & 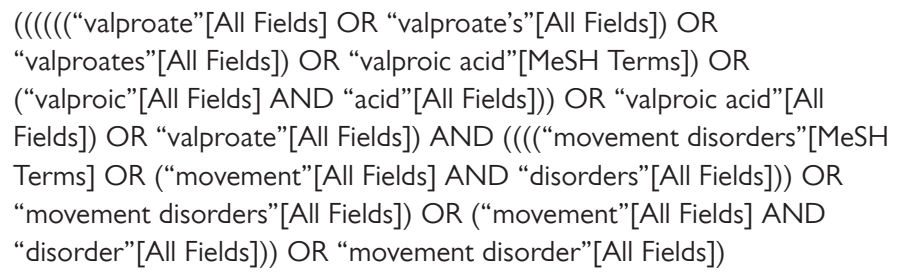 & 466 \\
\hline Total & & 3043 \\
\hline
\end{tabular}


of all papers found in the initial search. Disagreements between the authors were resolved through discussion.

Cases where the cause of MD was already known and either motor symptoms did not worsen or were not related to VPA were excluded. Also, cases that were not accessible by electronic methods, even after a formal request to the authors (by e-mail) were excluded. Reports that had more than one factor contributing to the MD were evaluated by the probability of occurrence of the event based on the Naranjo algorithm.

\section{Data extraction}

For VPA a total of 6,443 papers were found; 5,279 were irrelevant and 1,026 were unrelated to the complication, duplicate, inaccessible electronically, or provided insufficient data (Figure 3). Data abstraction was performed. When provided, we extracted author, department, year of publication, country of origin, number of patients affected, VPA indication including off-label uses, time from first VPA-dose until MD onset, time from VPA withdrawal or management to symptoms improvement, patient's status at the last follow-up, and important findings of clinical history and management. The majority of the reports did not provide specific

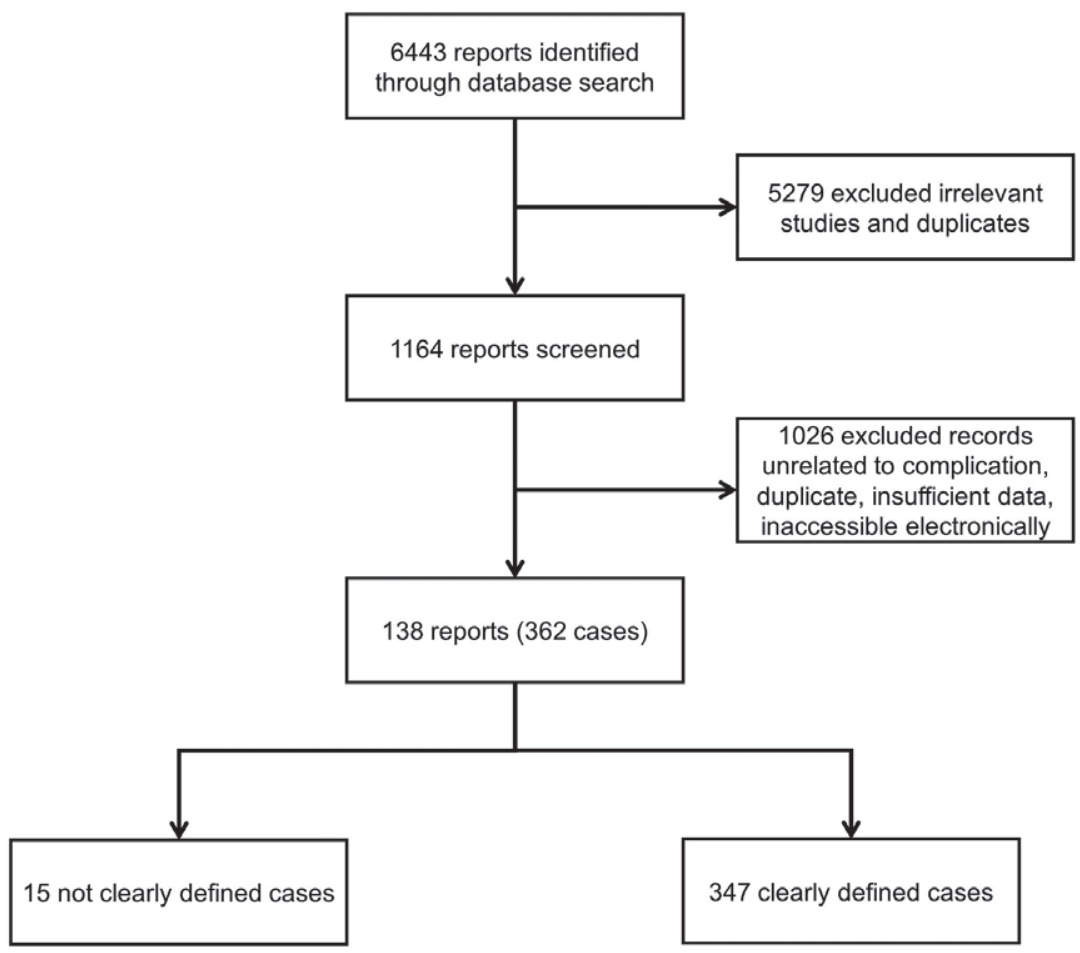

Figure 3 - Flow chart of the screening process for valproate (VPA). 
information about the times of MD onset and recovery. Data were extracted by two independent authors, double-checked to ensure matching, and organized by whether or not the MD was a side effect of VPA use.

\section{Statistical analysis}

Categorical variables were represented as proportions; continuous variables were represented as mean, standard deviation (SD), median, and range.

\section{Definitions}

The clinical characteristics and definitions of the MDs such as parkinsonism, tics, dyskinesia, dystonia, myoclonus, restless legs syndrome, akathisia, tremor, chorea, ataxia, and ballism were obtained from the reference Jankovic and Tolosa (2007). The clinical diagnosis for the psychiatric conditions was obtained from the Diagnostic and Statistical Manual of Mental Disorders (DSM- ${ }^{\circledR}$ ) (American Psychiatric Association, 2013). The Naranjo algorithm was used for determining the likelihood of whether an adverse drug reaction was actually due to the drug rather than the result of other factors (Naranjo et al., 1981). In the cases where the non-English literature was beyond the authors' proficiency (English, Portuguese, Spanish, Italian, French, and German) and the English abstract did not provide enough data, such as Japanese, Korean, Chinese, Russian, and Dutch, Google Translate service was used (De Vries et al., 2018).

\section{Results}

For the years 1975 to 2019, a total of 138 reports containing 362 cases, from thirtythree countries, of individuals who developed a movement disorder (MD) secondary to valproate (VPA) were reported (Table 2). Figure 4 shows the number of reports

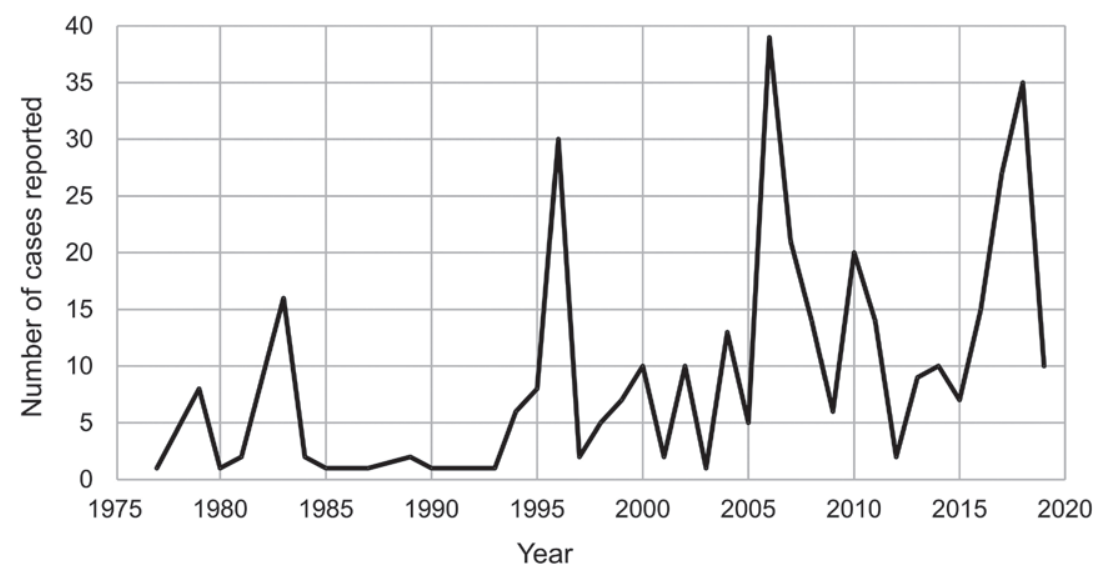

Figure 4 - Graphic showing the number of clinical reports of valproate (VPA)-associated movement disorders (MD) from 1975 to 2019. 


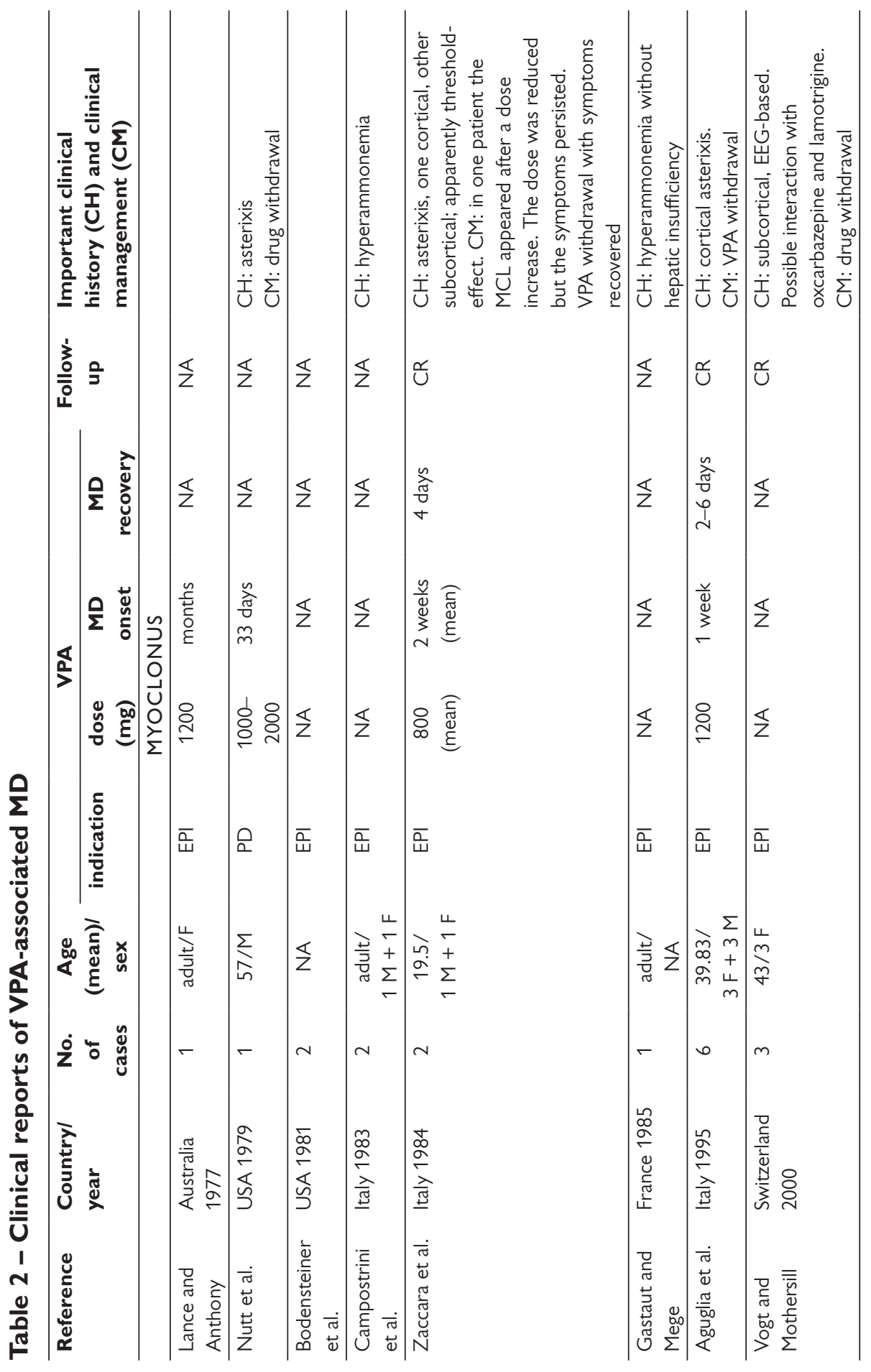




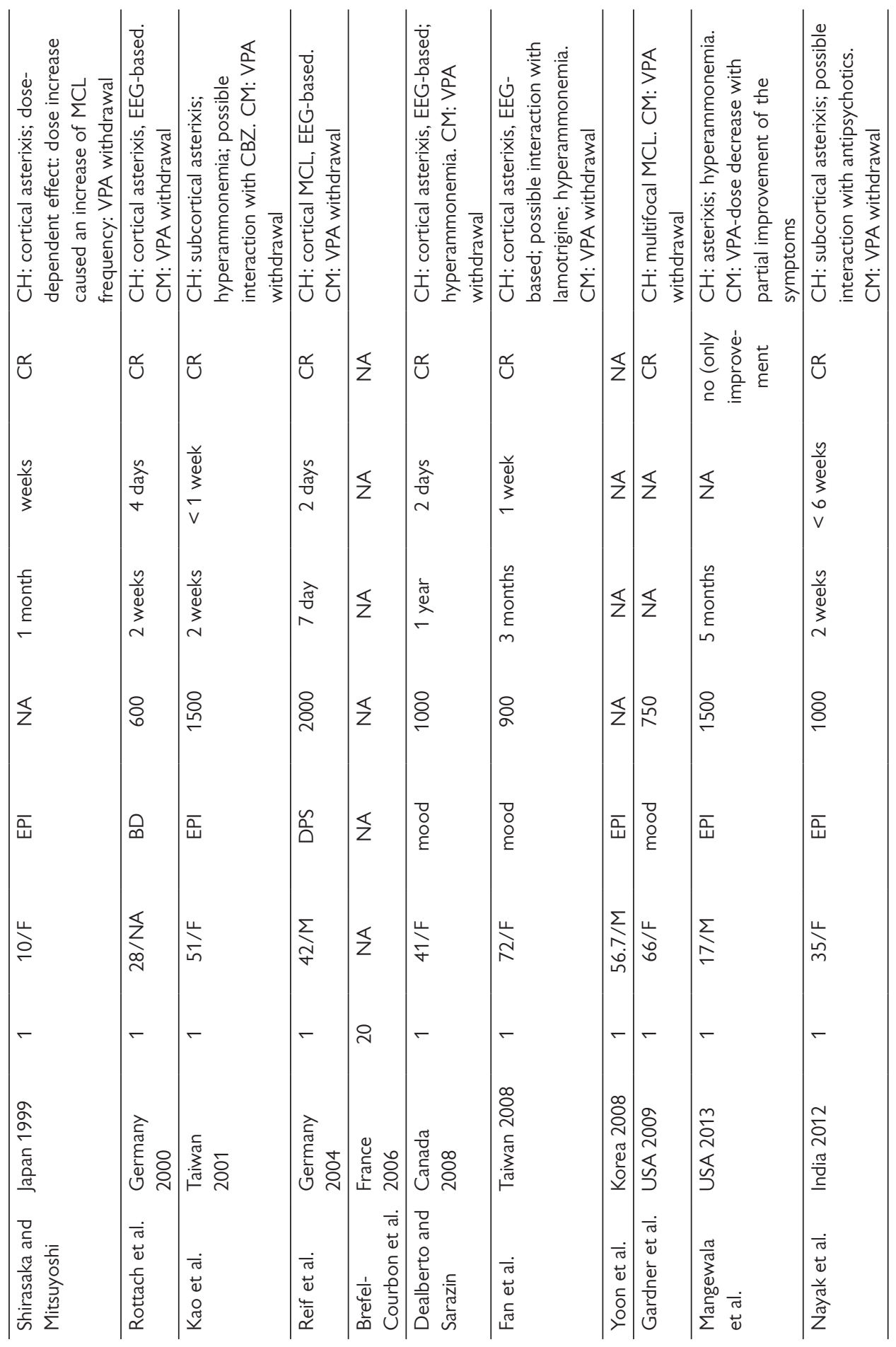


150) Prague Medical Report / Vol. 122 (2021) No. 3, p. 140-180

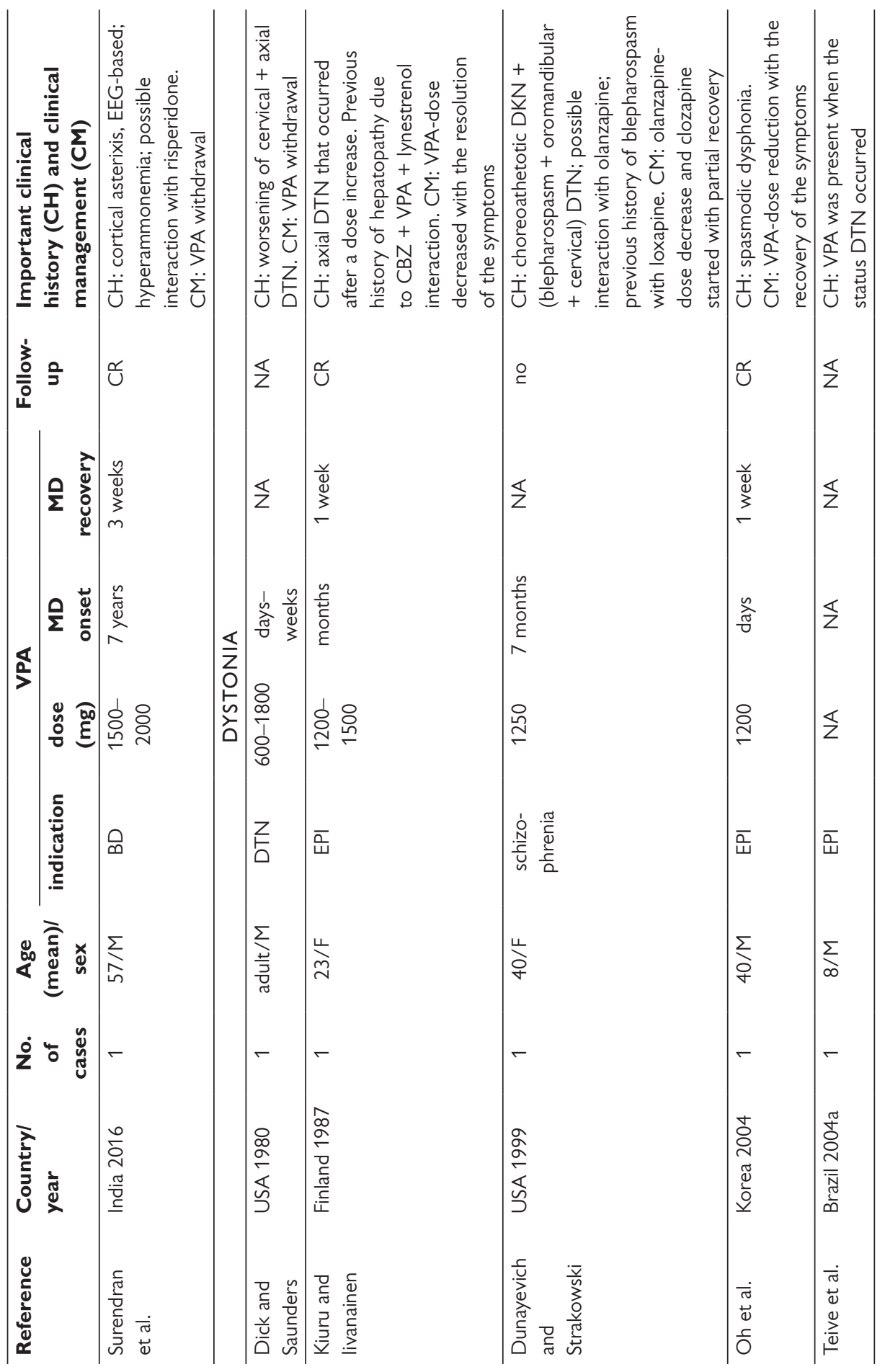

Rissardo J. P.; Caprara A. L. F.; Durante Í. 


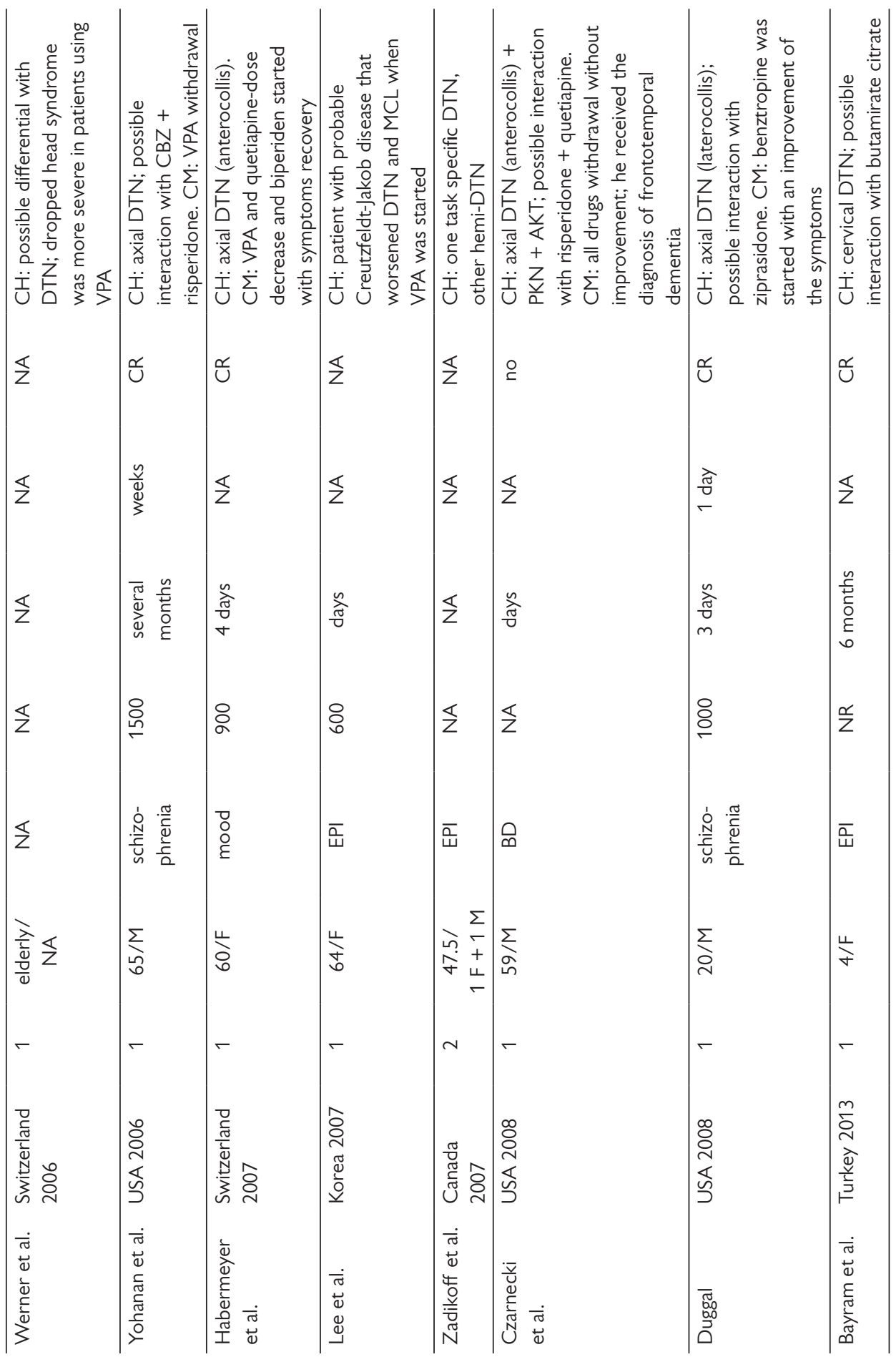




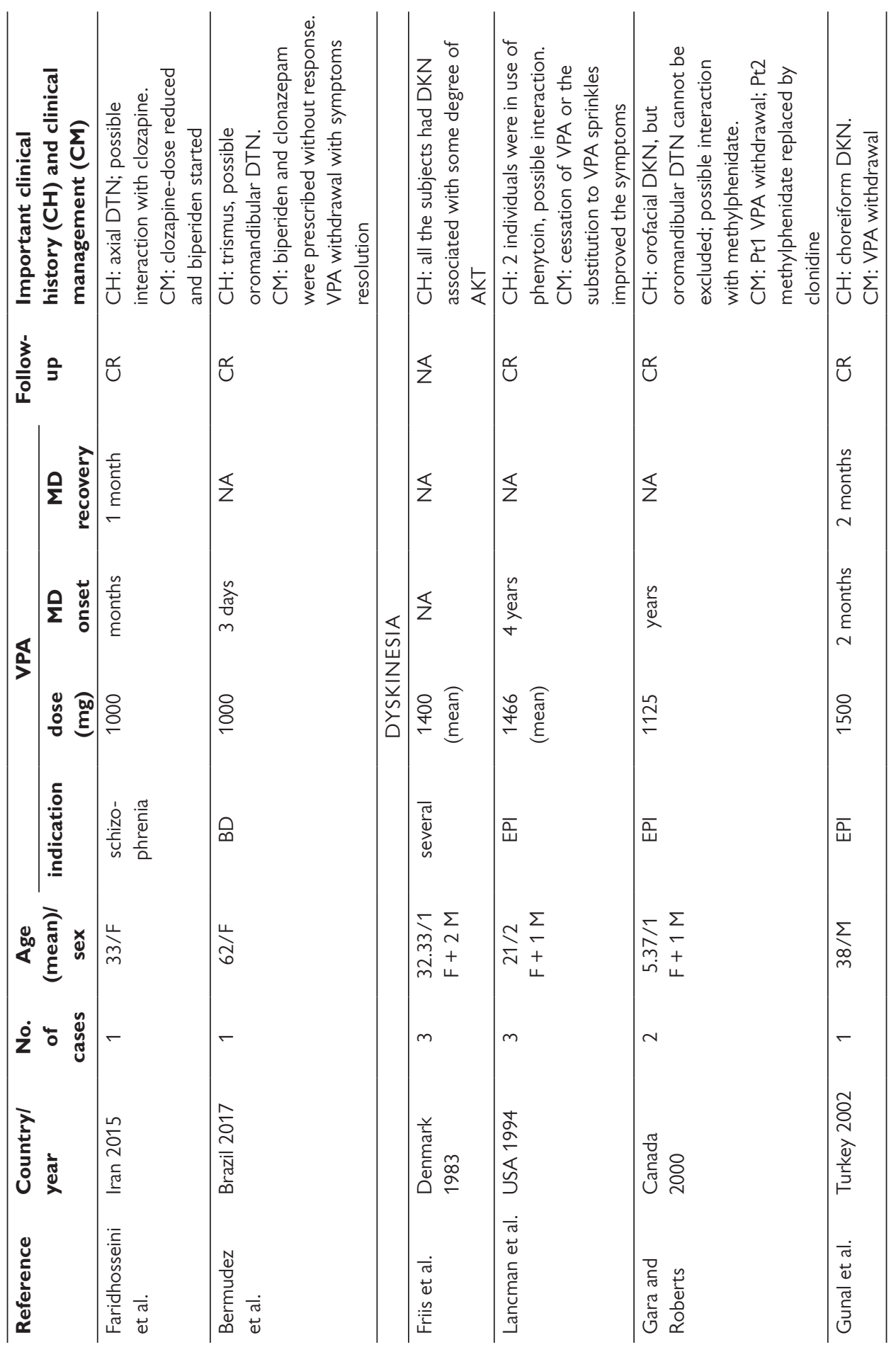

Rissardo J. P.; Caprara A. L. F.; Durante Í. 


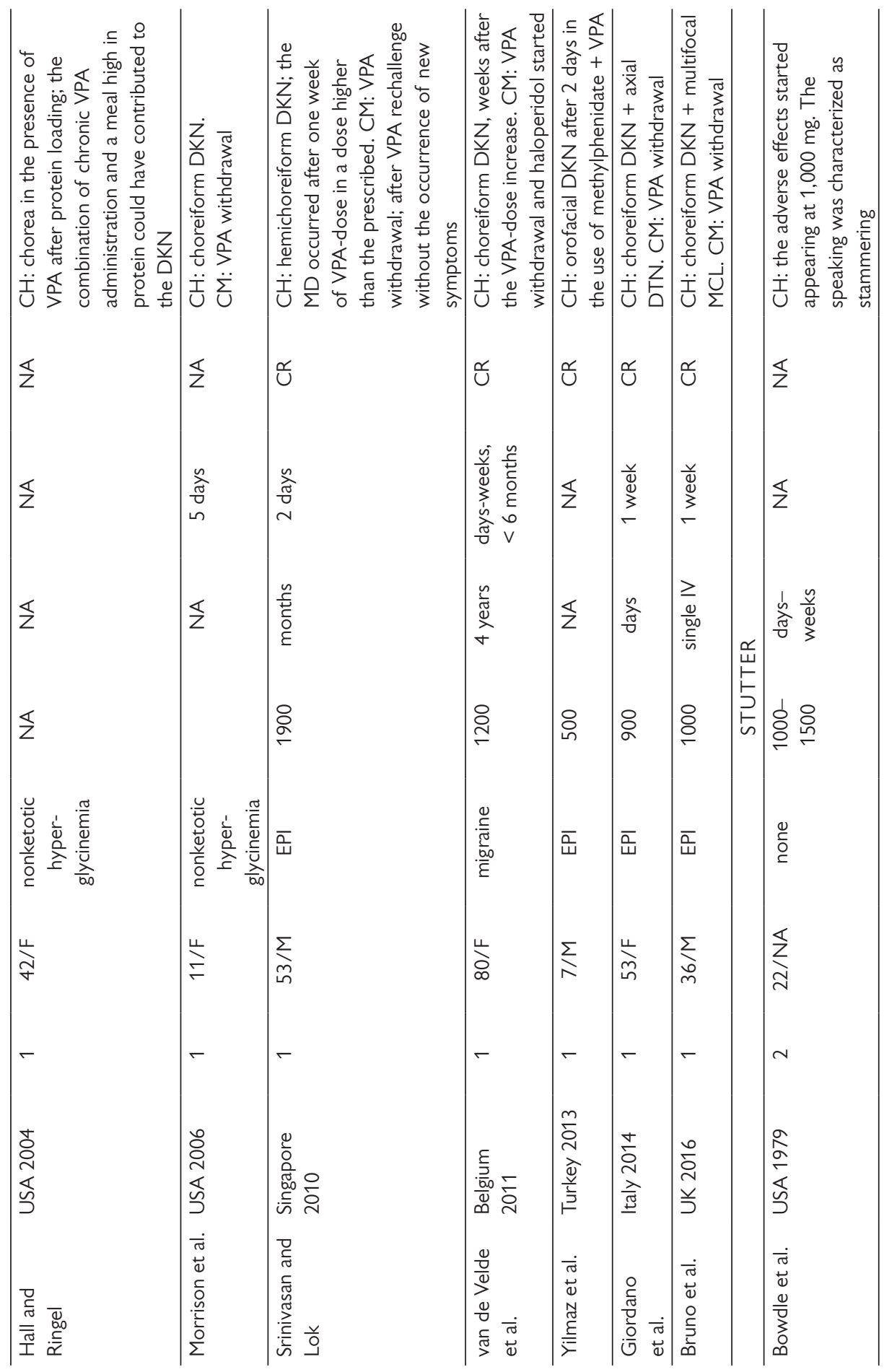


154) Prague Medical Report / Vol. 122 (2021) No. 3, p. 140-180

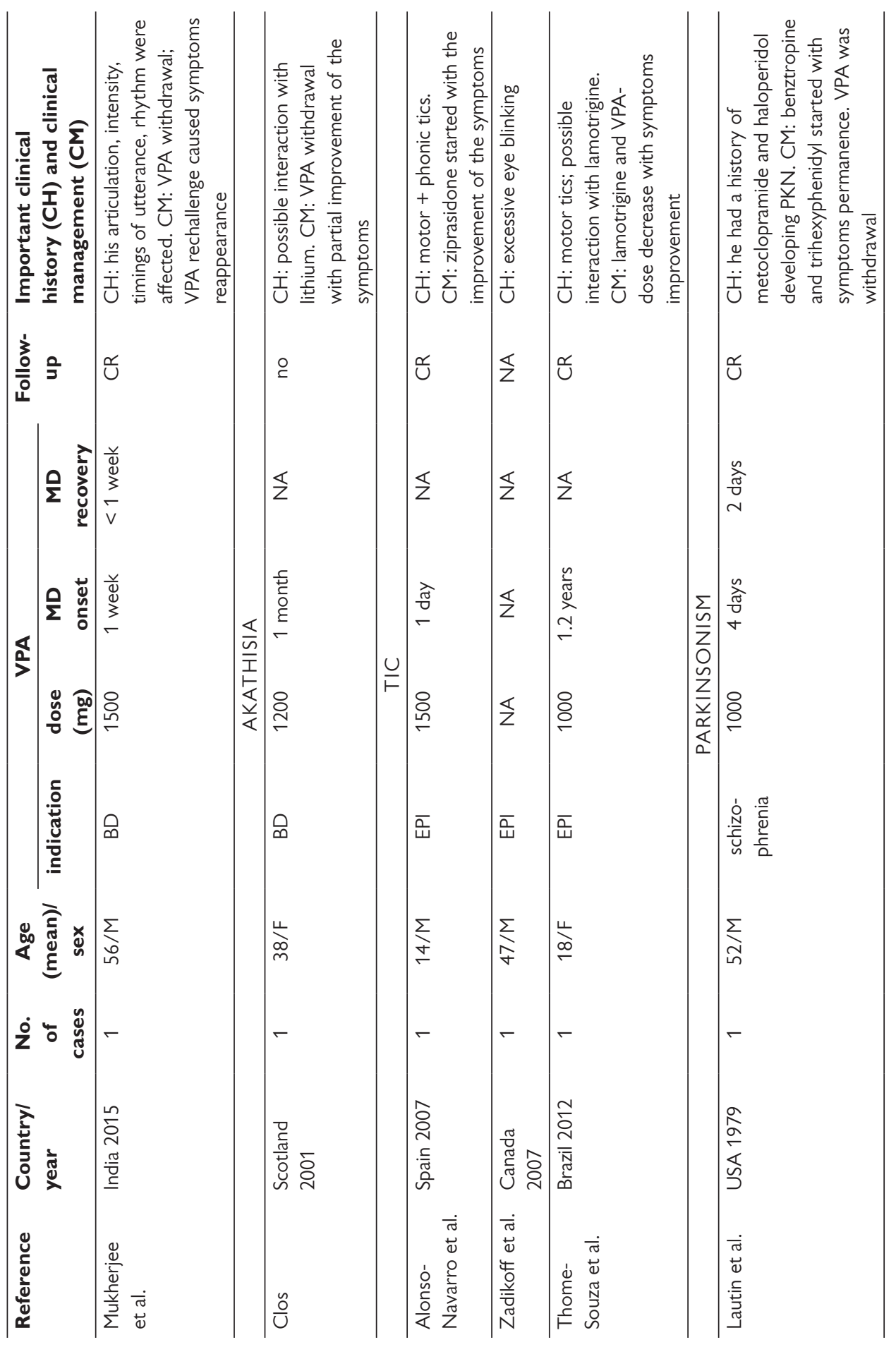

Rissardo J. P.; Caprara A. L. F.; Durante Í. 


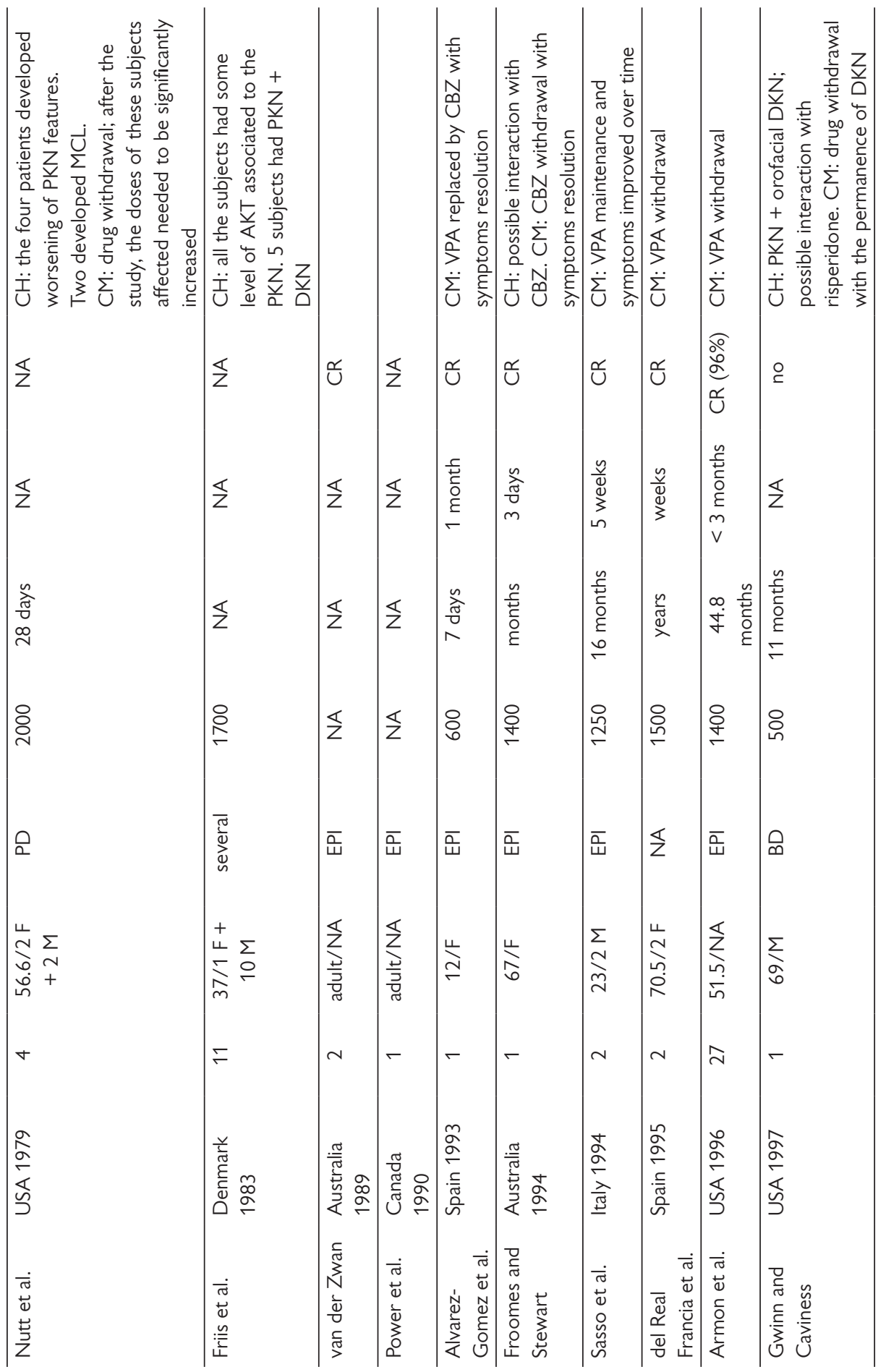


156) Prague Medical Report / Vol. 122 (2021) No. 3, p. 140-180

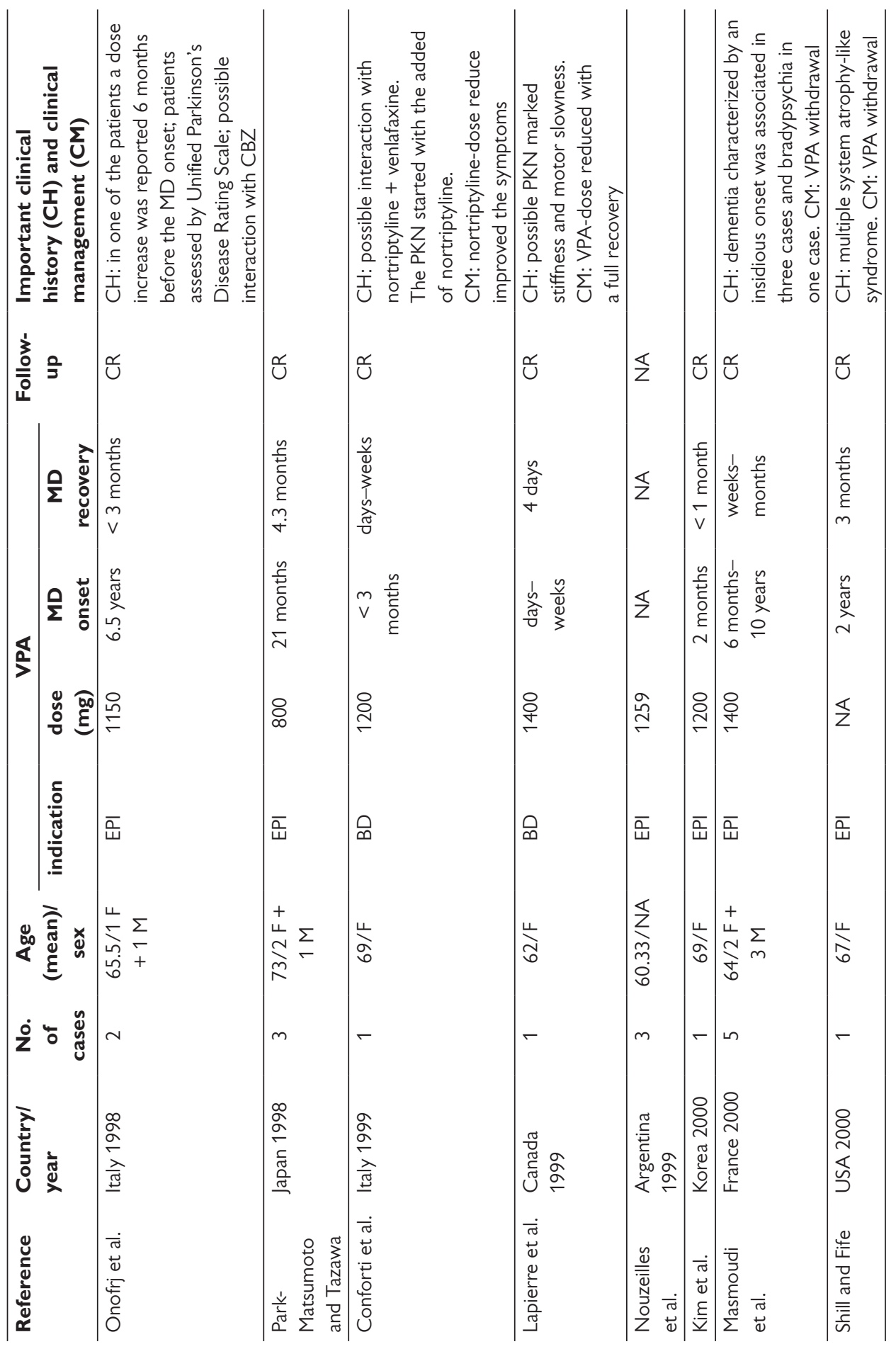

Rissardo J. P.; Caprara A. L. F.; Durante Í. 


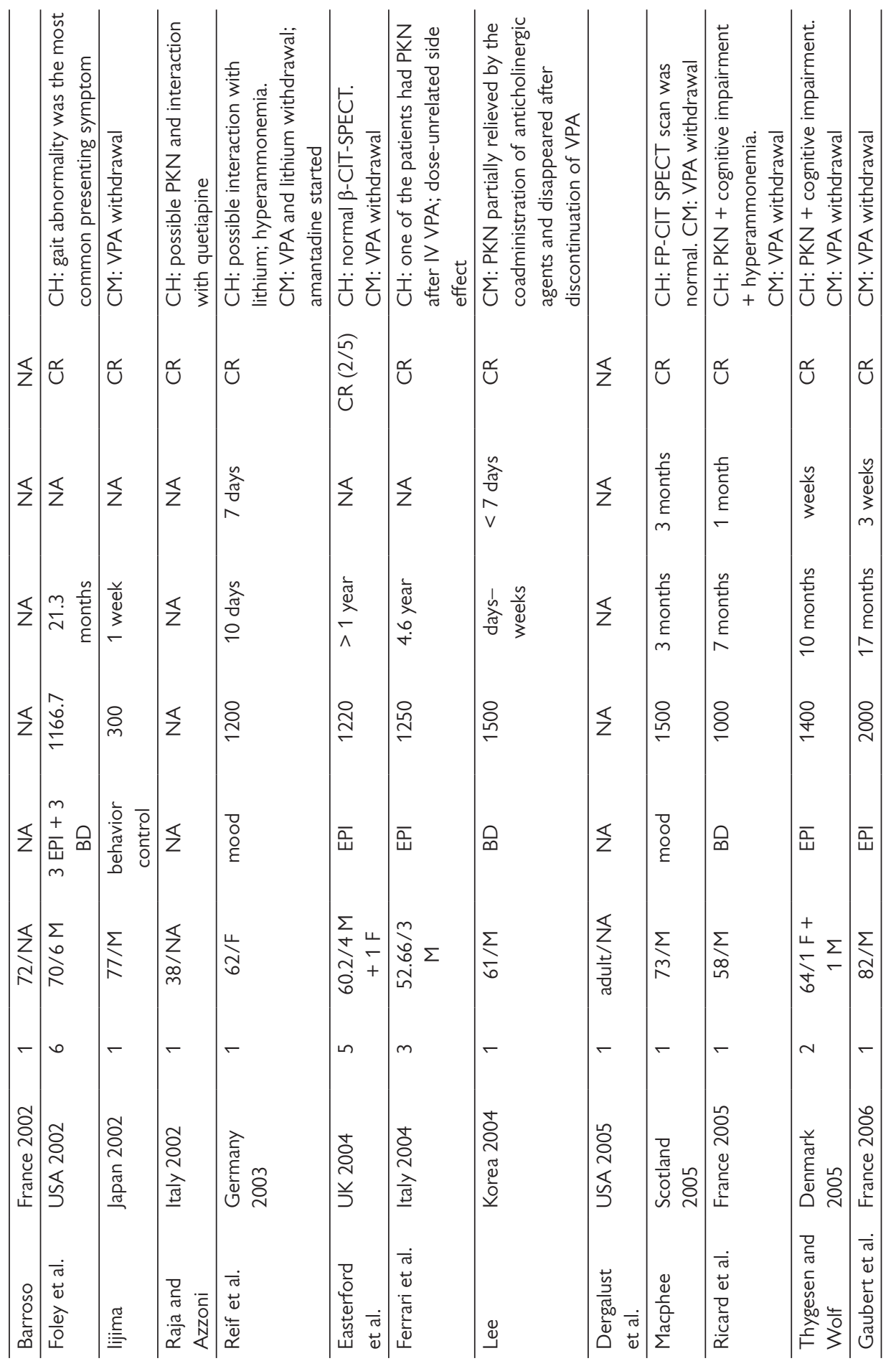


158) Prague Medical Report / Vol. 122 (2021) No. 3, p. 140-180

\begin{tabular}{|c|c|c|c|c|c|c|c|c|c|}
\hline 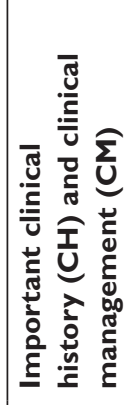 & 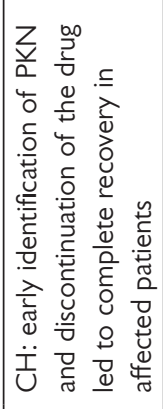 & 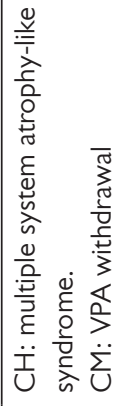 & 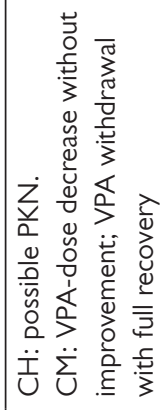 & & 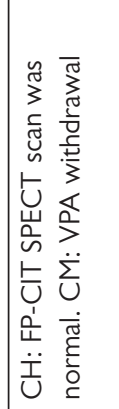 & & & 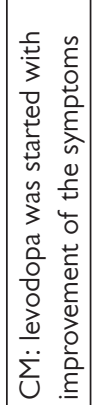 & 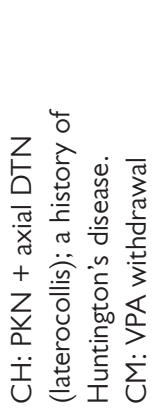 \\
\hline ”o & 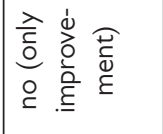 & 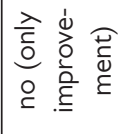 & 唄 & 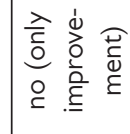 & 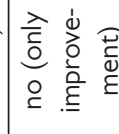 & $\S$ & $\S$ & Z & $\stackrel{\mathscr{U}}{\cup}$ \\
\hline 号 & $\S$ & 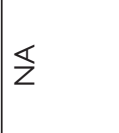 & 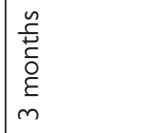 & 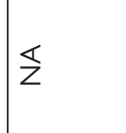 & 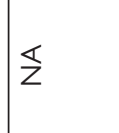 & ¿ & ¿ & ¿ & 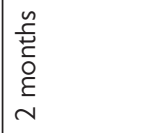 \\
\hline 号 总 & 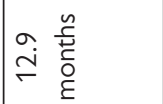 & 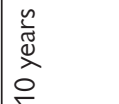 & 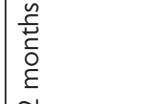 & 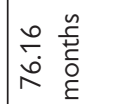 & 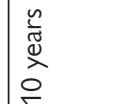 & 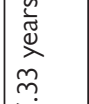 & 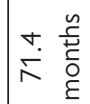 & \& & 瓷 \\
\hline 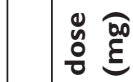 & $\stackrel{8}{\circ}$ & 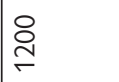 & 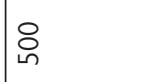 & 只 & ৪্ণ & $\stackrel{\stackrel{\sim}{q}}{\underset{\sim}{\leftarrow}}$ & $\mathbb{z}$ & ষ্ণ & 웅 \\
\hline $\mid$ & 혼 & $\overline{\mathrm{s}}$ & $\overline{\mathrm{I}}$ & $\overline{\mathrm{u}}$ & $\overline{\bar{y}}$ & $\overline{\mathrm{L}}$ & ¿ & $\overline{\bar{山}}$ & $\begin{array}{l}8 \\
0 \\
0 \\
8\end{array}$ \\
\hline 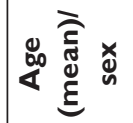 & 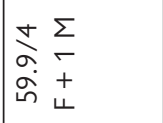 & $\frac{4}{6}$ & $\sum_{\infty}$ & 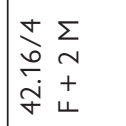 & $\frac{4}{6}$ & $\begin{array}{ll}\forall & \Sigma \\
\omega & \sim \\
\sim & + \\
\forall & + \\
\sqcup\end{array}$ & 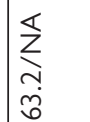 & $\sum_{n}^{\Sigma}$ & $\sum_{i}$ \\
\hline$\dot{z} \overline{0} \stackrel{y}{u}$ & in & - & - & 0 & - & 0 & $\nabla$ & - & - \\
\hline 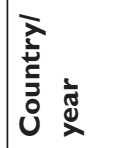 & 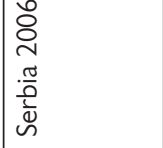 & 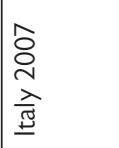 & 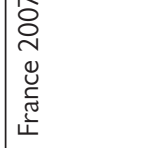 & 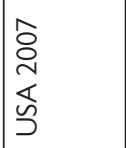 & 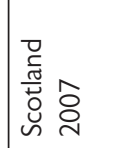 & 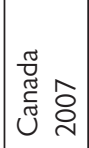 & 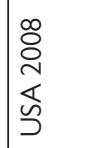 & 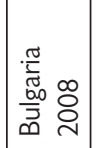 & 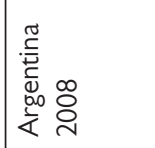 \\
\hline 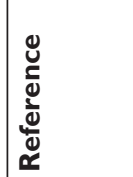 & 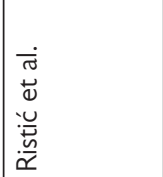 & 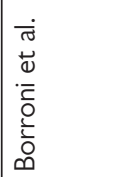 & 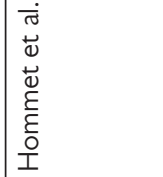 & 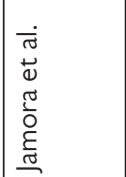 & 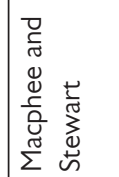 & 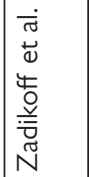 & 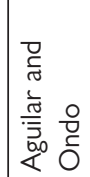 & 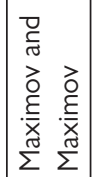 & 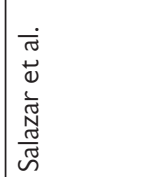 \\
\hline
\end{tabular}




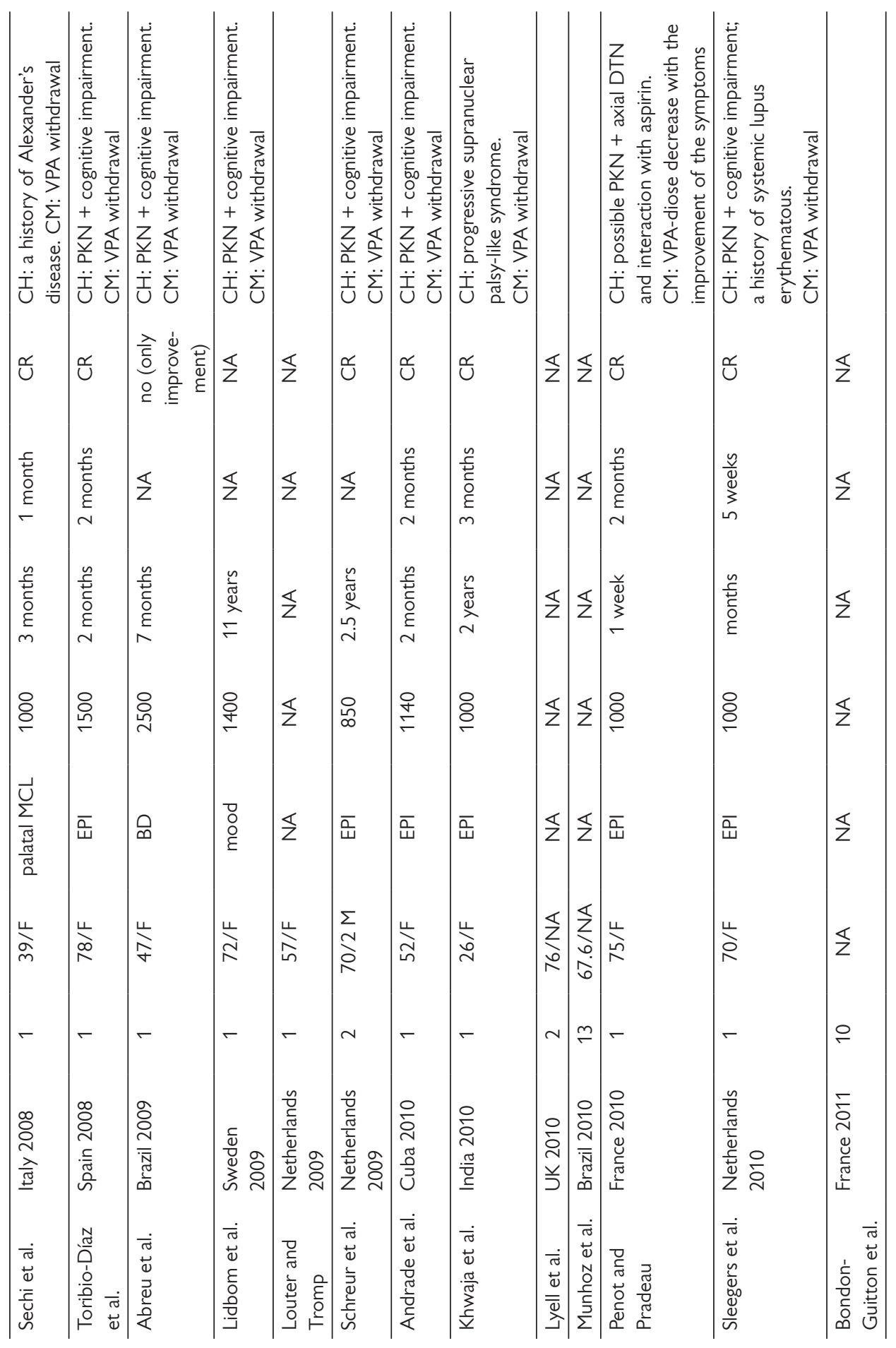


160) Prague Medical Report / Vol. 122 (2021) No. 3, p. 140-180

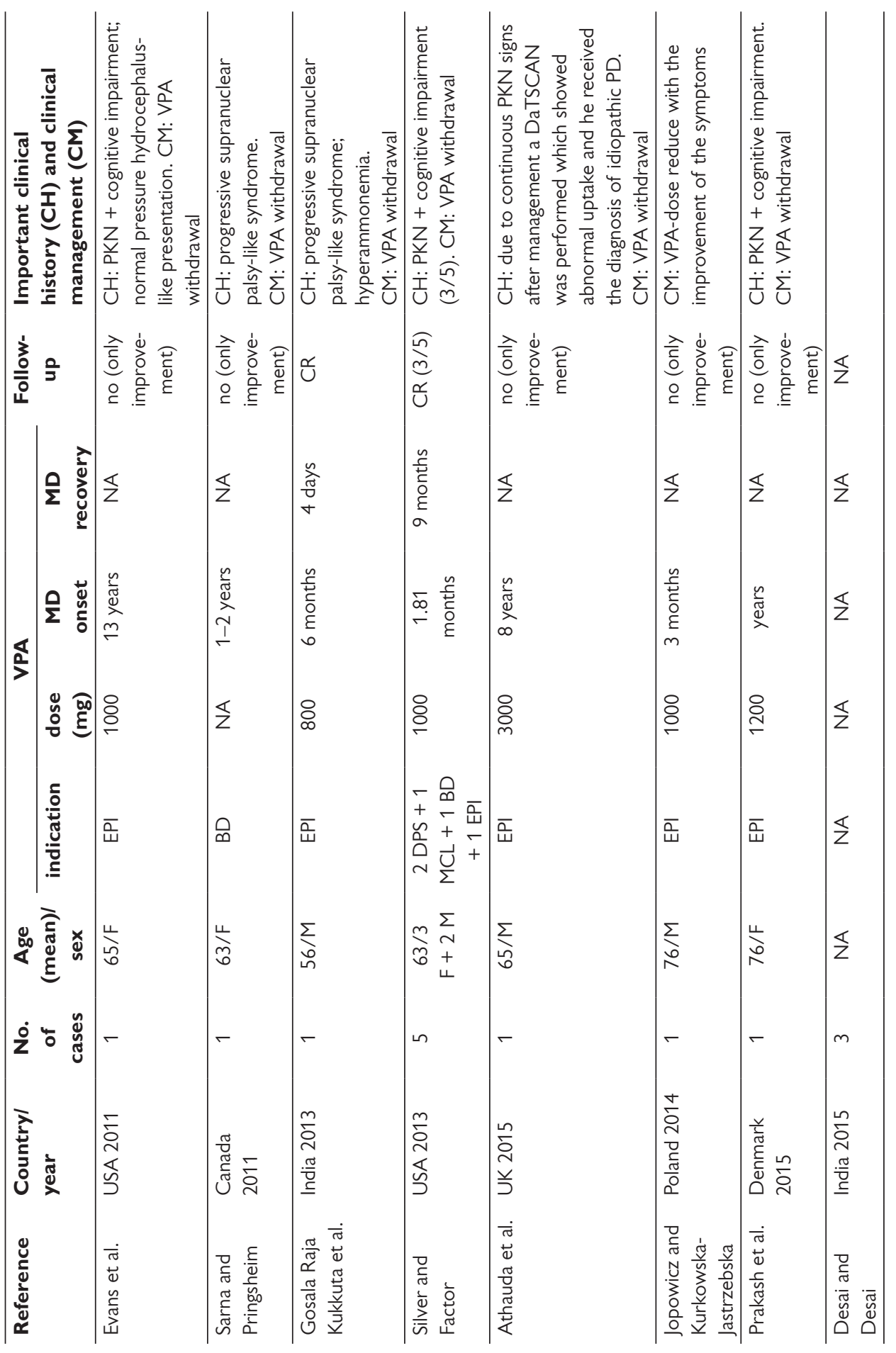

Rissardo J. P.; Caprara A. L. F.; Durante Í. 


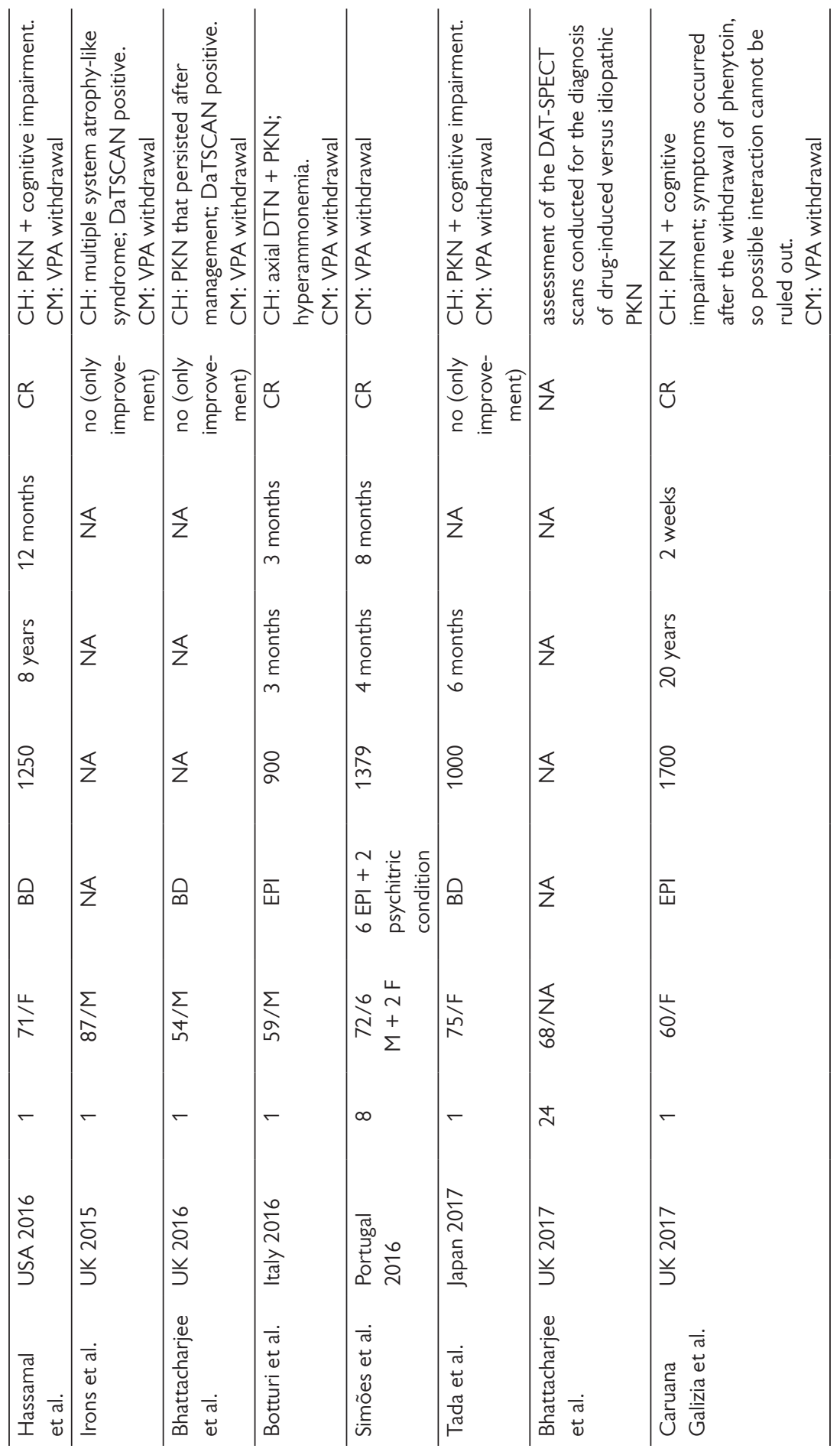




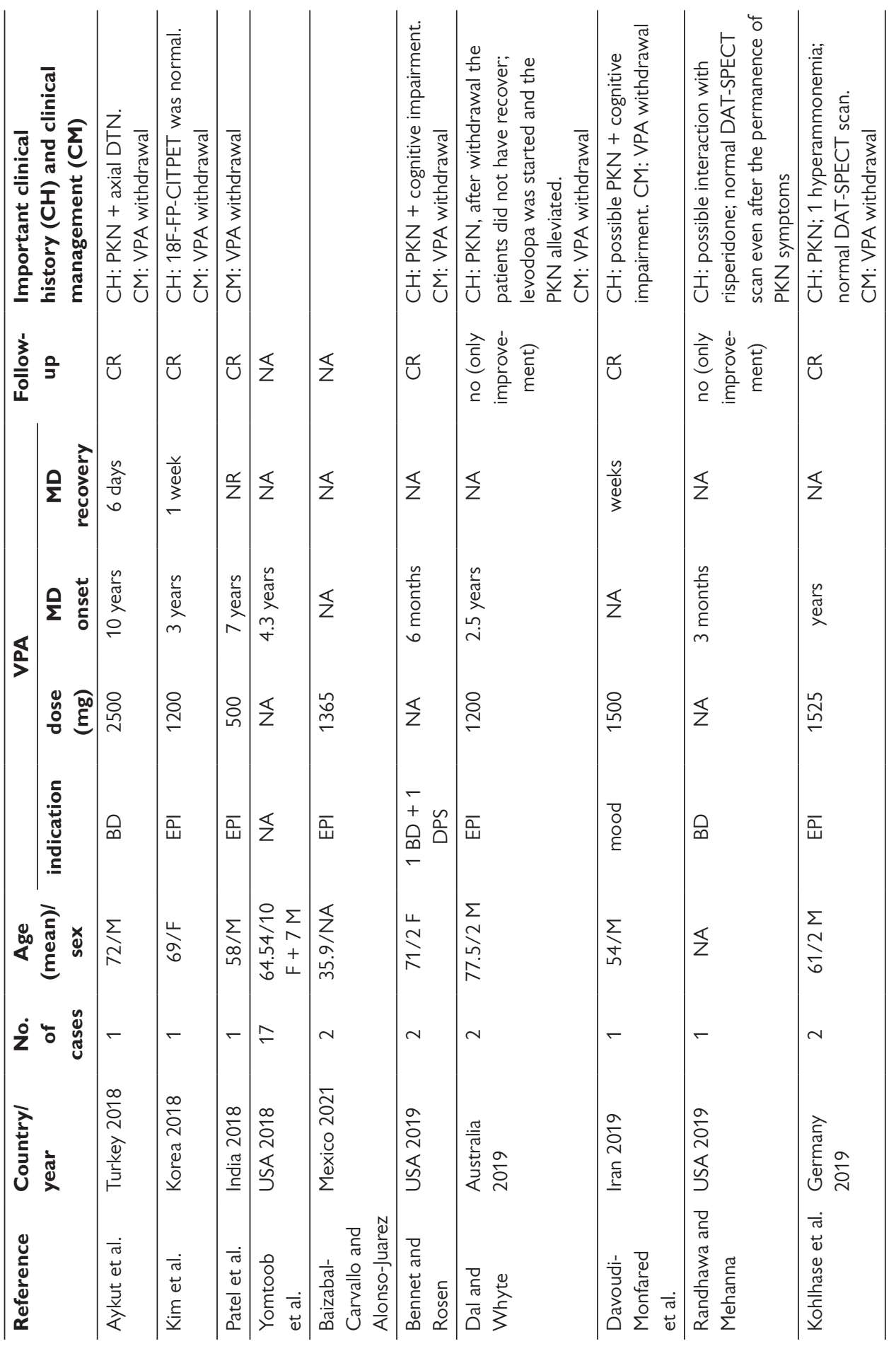

Rissardo J. P.; Caprara A. L. F.; Durante Í. 


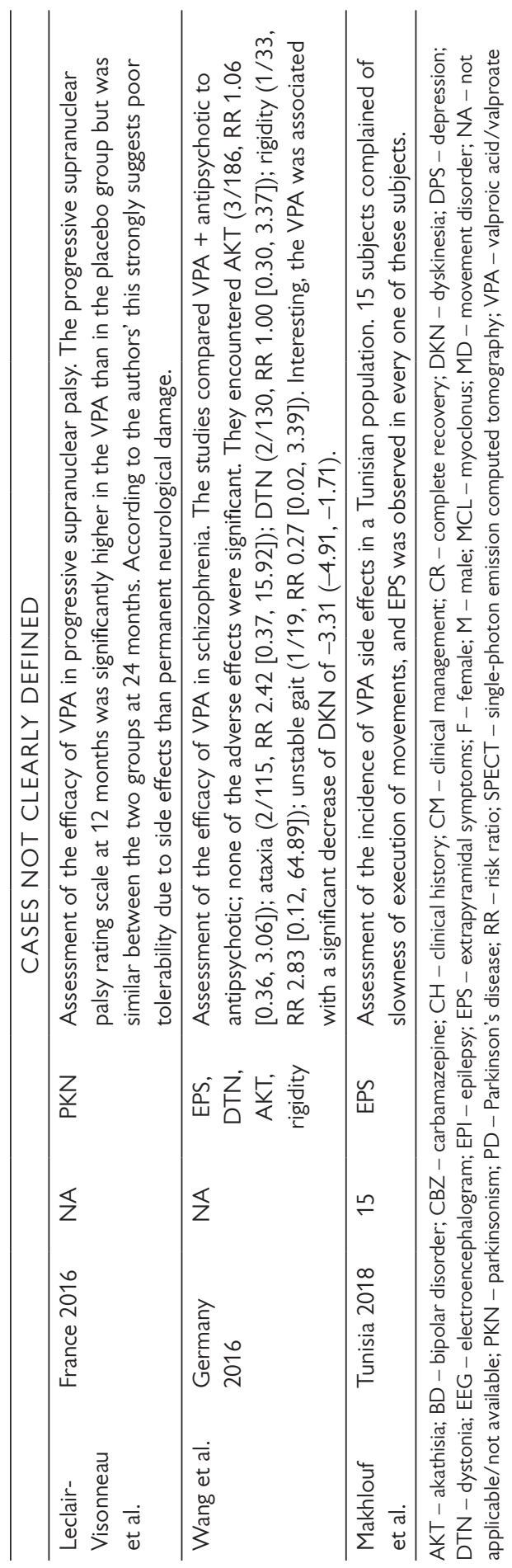




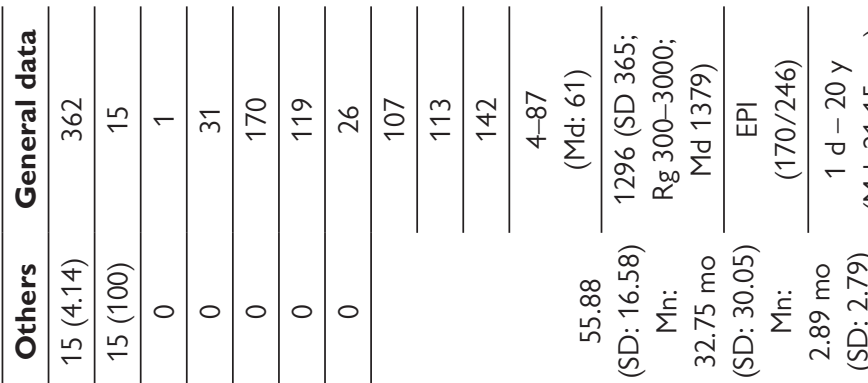

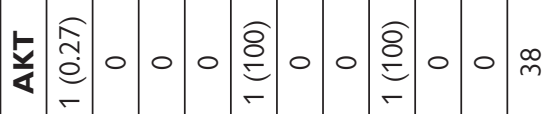

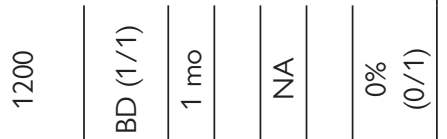

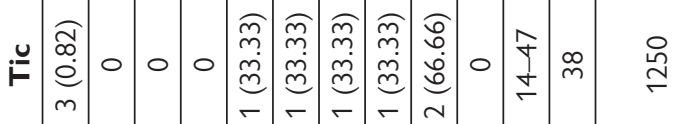

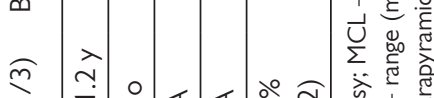

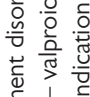

วั

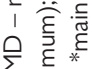

实

은

हो

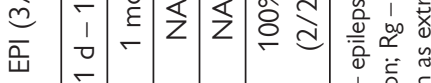

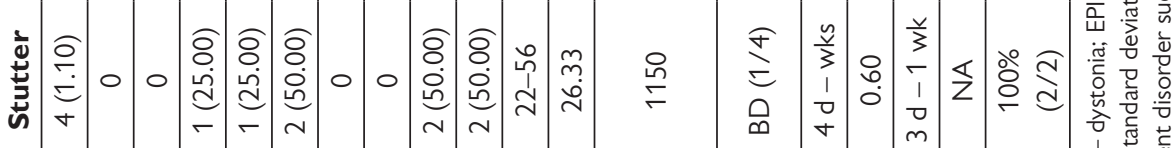

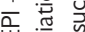

तो 密

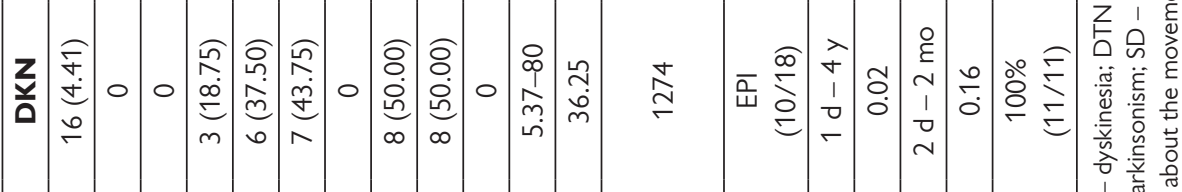

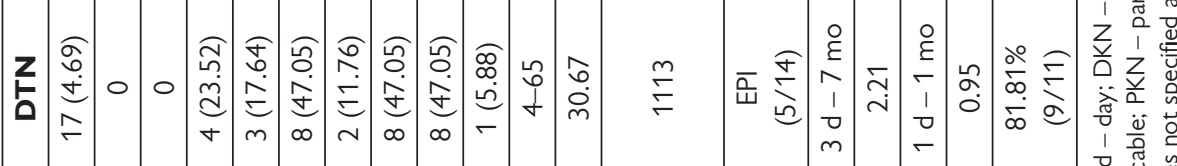

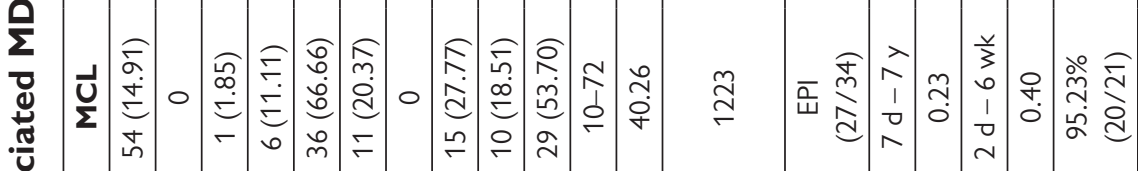

空言总

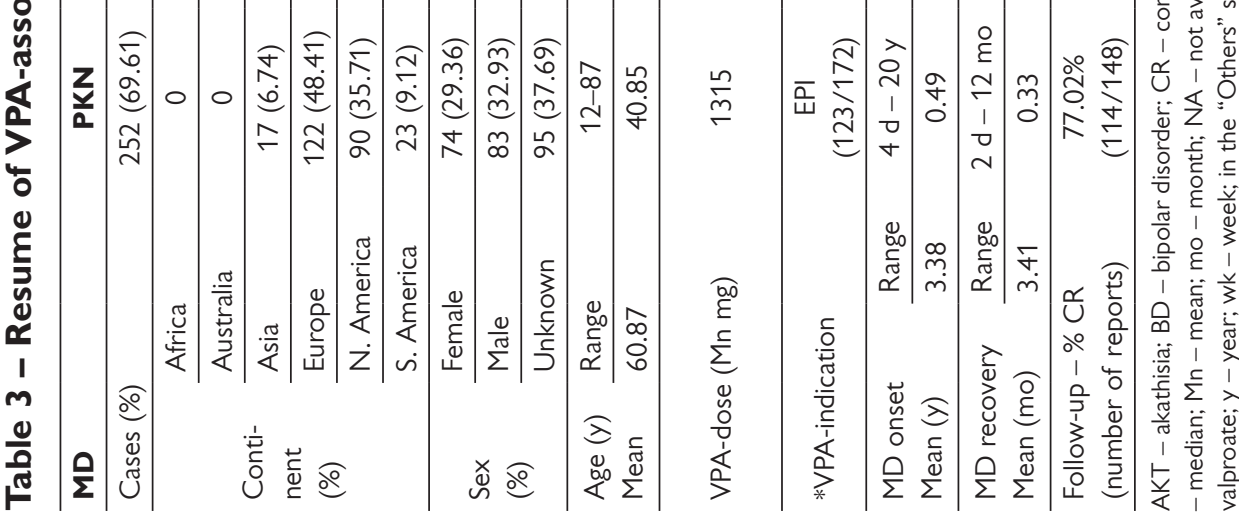

Rissardo J. P.; Caprara A. L. F.; Durante Í. 
of VPA-associated MD over time. There were 170 reports from Europe, 119 North American, 31 Asian, 26 South American, 15 African, and 1 Australian. The MDs identified were parkinsonism, with 252 cases, 54 cases of myoclonus, 17 of dystonia (DTN), 16 of dyskinesia, 4 of stutters, 3 of tics, and 1 of akathisia (AKT). In the "not clearly defined group", 15 cases of extrapyramidal symptoms, 3 of AKT, 2 of DTN, 1 of rigidity, and 1 of unstable gait were assessed.

The summary data about VPA-associated MD is provided in Table 3. Herein, we will describe the general data of all clearly defined cases.

The abnormal movements occurred in males in $51.36 \%$ of the cases. The mean and median age was 55.8 (SD: 16.58) and 61 years (age range: 4-87 years). The indication of VPA in descending order of frequency was epilepsy $69.10 \%$ (170/246), bipolar disorder (25), "mood related" (12), DKN (dyskinesia) in Parkinson's disease (5), schizophrenia (5), depression (4), myoclonus (MCL) (2), DTN (1), migraine (1), twitch eyelids (1), and others non-specified psychiatric conditions (20).

The mean and median time from starting VPA use to the MD onset was 32.75 (SD: 30.05 ) and 21.15 months (MD onset time range: 1 day -20 years), respectively. About $75 \%$ of the individual had abnormal movement within 50 months of the VPA treatment. The mean and median time from the VPA withdrawal until the MD recovery was 2.89 (SD: 2.79) and 3 months (MD recovery time range: 1 day 12 months), respectively. In the subgroup of subjects that had improvement of the symptoms, the complete recovery was achieved within 9 months of the drug withdrawal in almost all cases (99\%). Figure 5 shows a comparison between the percentage of patients who developed a MD since the beginning of the treatment and the percentage of patients recovering after drug withdrawal when outliers were removed.
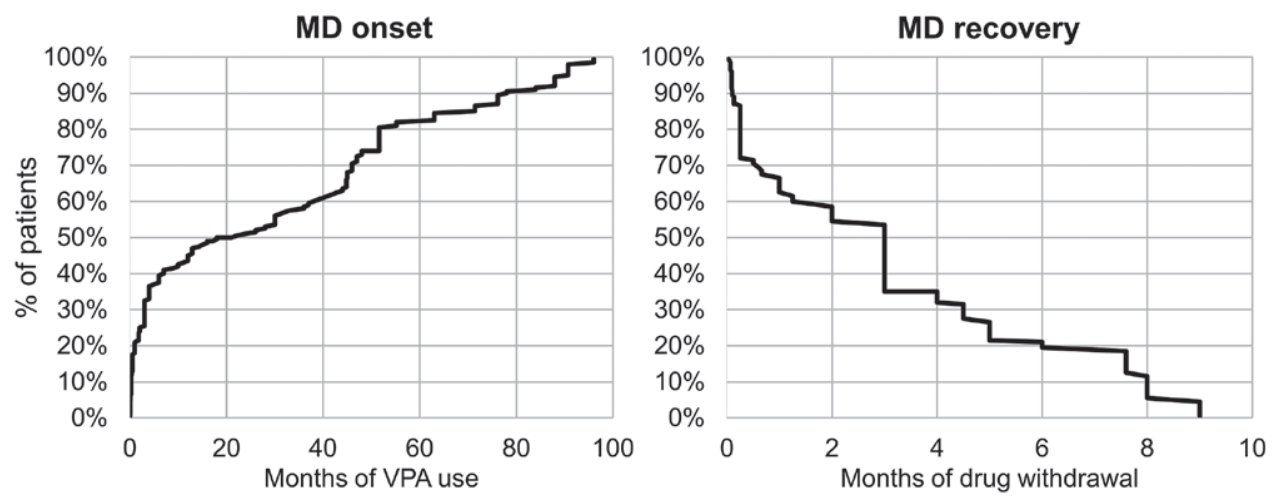

Figure 5 - Comparison between the percentage of patients developing movement disorders (MD) since the beginning of the drug treatment and the percentage of patients recovering after drug withdrawal. 
The most common management was drug withdrawal. Other options were the VPA-dose reduction, replacement of the drug probably interacting with VPA, and the prescription of other drugs after the VPA discontinuation, such as levodopa, benztropine, benzodiazepines, biperiden, haloperidol, and diphenhydramine. In addition, the replacement of VPA in tablet form for the same dosage in sprinkles presentation was sufficient to improve the symptoms in one case. A complete recovery was observed in $80.61 \%$ of the patients $(158 / 196)$.

\section{Discussion}

\section{General}

VPA-associated MD was widely reported in the literature. We believe that the availability, costs, and some historical factors of VPA probably had contributed to this. VPA is among the safest and most effective medicines needed in a health system, as attested by the World Health Organization's List of Essential Medicines, and it is marketed in the majority of countries. Also, VPA was the $126^{\text {th }}$ most prescribed medication in the USA with almost six million prescriptions in 2017 (ClinCalc, 2020). Furthermore, the well-known description of flunarizine and cinnarizine developing PKN in 1984, promoted the awareness of the drug-induced $\mathrm{MD}$ resulting in an increasing number of reports about all abnormal movements secondary to medications including those associated with VPA (Teive et al., 2004b).

Based on the data available in Table 2, we can hypothetically illustrate a case. A middle-aged European male with poorly controlled epilepsy resorts to his neurologist. VPA $250 \mathrm{mg}$ with a gradual increase until five-six tablets a day was prescribed. Within three years, the patient started complaining of stiffness, rigidity, and resting tremor; neurological examination revealed bradykinesia, and a diagnosis of PKN secondary to VPA was done. VPA was established and lamotrigine or carbamazepine was started. In the follow-up after three months, the patient had a full recovery and was able to walk without assistance and the tremor disappeared.

The majority of the incidences of abnormal movements associated with VPA are not well described in the literature. Table 3 is a summary of the percentages of some abnormal movements secondary to VPA (Anthony, 1977; Bowdle et al., 1979; Friis et al., 1983; Zaccara et al., 1984; van der Zwan, 1989; Armon et al., 1996; Nouzeilles et al., 1999; Easterford et al., 2004; Ristić et al., 2006; Jamora et al., 2007; Zadikoff et al., 2007; Lance and; Leclair-Visonneau et al., 2016; Makhlouf et al., 2018; Baizabal-Carvallo and Alonso-Juarez, 2021); the data was extracted from the clinical trials and population-based studies that provide sufficient data for Table 2. The incidences of VPA-associated abnormal movements extensively vary throughout the literature. For example, VPA-induced PKN was observed from 1.37 to $75 \%$ of the individuals.

Herein, we would like to discuss some of the MDs in subtopics to allow a better comprehension of the data. 


\section{Parkinsonism (PKN) \\ History}

In 1979, Lautin et al. reported the first case of VPA-induced PKN. They described a middle-aged male who was prescribed VPA 1,000 mg for schizophrenia; four days later, the patient complained of PKN symptoms. Benztropine and trihexyphenidyl were started, but the symptoms did not alleviate. Only when VPA was withdrawn the patient had a full recovery. Also, the individual had a previous history of PKN secondary to metoclopramide and haloperidol. Therefore, we believe that this has contributed significantly to the literature because a similar presentation of VPA and antidopaminergic drugs in the same individual suggested a common neuronal pathway associated with extrapyramidal symptoms of these two drug classes. It is worth mentioning that in the same year Nutt et al. (1979) published the cases of four individuals with Parkinson's disease with worsening gait and resting tremors that were using VPA.

\section{Epidemiology}

The incidence of PKN following VPA use found in the literature was 1.37, 1.60, $2.27,5.04,6.00,10.16,10.71,73.33$, and $75.00 \%$ (Table 4 ). The majority of the individuals reported were males, the mean age was 60.87 years, the mean VPAdose was $1,315 \mathrm{mg}$. The time since starting VPA until MD onset, and the time until resolution after VPA discontinuation were 3.38 years and 3.41 months, respectively. When we compare the present study with the Brugger et al. (2016); the main differences encountered are that the present work has assessed a greater number of patients (252 vs. 116), of which the majority was male (52.86\% vs. $41.4 \%)$; interestingly, the findings of Brugger et al. (2016) for mean age (63.5 years), VPA main indication (epilepsy) and median VPA dose $(1,250 \mathrm{mg})$ were almost identical to those already described in this revision.

\section{Presentation and clinical diagnosis}

The presentation in the majority of the cases was a symmetric akinetic-rigid syndrome, with predominant postural/action over the resting tremor. Sometimes signs and symptoms of cognitive impairment were observed. The severity of the clinical presentation ranged from mild to severe with loss of physical independence. Some patients had pre-existing diseases other than the indication for VPA prescription such as Parkinson's disease, multiple system atrophy, progressive supranuclear palsy, Huntington's disease, systemic lupus erythematosus, and some brain damage. Interestingly, multiple system atrophy-like and progressive supranuclear palsy-like syndromes were reported as the presenting symptoms. A clear distinction between VPA-induced MD and idiopathic Parkinson's disease based only on clinical criteria is challenging in clinical practice. Therefore, we proposed some clinical tools to help with the diagnosis of this syndrome (Table 5). 
168) Prague Medical Report / Vol. 122 (2021) No. 3, p. 140-180

\section{Table 4 - Incidence of some abnormal movements associated with VPA in the literature}

\begin{tabular}{|c|c|c|c|c|c|c|}
\hline MD & Reference & Year & NR & $\mathbf{N}$ & $\begin{array}{c}\text { Incidence } \\
\text { (\%) }\end{array}$ & $\begin{array}{l}\text { Studied } \\
\text { disease }\end{array}$ \\
\hline MCL & Lance and Anthony & 1977 & 1 & 60 & 1.66 & EPI \\
\hline Ataxia & Lance and Anthony & 1977 & 1 & 60 & 1.66 & EPI \\
\hline Tremor & Lance and Anthony & 1977 & 2 & 60 & 3.33 & EPI \\
\hline Stutter & Bowdle et al. & 1979 & 2 & 6 & 33.33 & healthy \\
\hline AKT & Friis et al. & 1983 & 15 & 15 & 100.00 & several \\
\hline PKN & Friis et al. & 1983 & 11 & 15 & 73.33 & several \\
\hline DKN & Friis et al. & 1983 & 8 & 15 & 53.33 & several \\
\hline $\mathrm{MCL}$ & Zaccara et al. & 1984 & 2 & 38 & 5.26 & EPI \\
\hline PKN & van der Zwan & 1989 & 2 & 88 & 2.27 & EPI \\
\hline PKN & Armon et al. & 1996 & 27 & 36 & 75.00 & EPI \\
\hline Tremor & Armon et al. & 1996 & 16 & 36 & 44.44 & EPI \\
\hline Bradykinesia & Armon et al. & 1996 & 22 & 35 & 62.85 & EPI \\
\hline PKN & Nouzeilles et al. & 1999 & 3 & 28 & 10.71 & EPI \\
\hline $\begin{array}{l}\text { Intentional } \\
\text { tremor }\end{array}$ & Nouzeilles et al. & 1999 & 15 & 28 & 53.57 & EPI \\
\hline $\begin{array}{l}\text { Postural } \\
\text { tremor }\end{array}$ & Nouzeilles et al. & 1999 & 16 & 28 & 57.14 & EPI \\
\hline PKN & Easterford et al. & 2004 & 3 & 50 & 6.00 & EPI \\
\hline Tremor & Easterford et al. & 2004 & 11 & 50 & 22.00 & EPI \\
\hline PKN & Ristić et al. & 2006 & 5 & 364 & 1.37 & EPI \\
\hline Tremor & Ristić et al. & 2006 & 28 & 364 & 7.69 & EPI \\
\hline Ataxia & Ristić et al. & 2006 & 7 & 364 & 1.92 & EPI \\
\hline PKN & Jamora et al. & 2007 & 6 & 119 & 5.04 & EPI \\
\hline PKN & Zadikoff et al. & 2007 & 6 & 59 & 10.16 & EPI \\
\hline $\begin{array}{l}\text { Postural/ } \\
\text { action tremor }\end{array}$ & Zadikoff et al. & 2007 & 6 & 59 & 10.16 & EPI \\
\hline DTN & Zadikoff et al. & 2007 & 2 & 59 & 3.38 & EPI \\
\hline Tic & Zadikoff et al. & 2007 & 1 & 59 & 1.69 & EPI \\
\hline $\begin{array}{l}\text { Worsening of } \\
\text { the gait }\end{array}$ & $\begin{array}{l}\text { Leclair-Visonneau } \\
\text { et al. }\end{array}$ & 2016 & 3 & 28 & 10.71 & PSP \\
\hline $\begin{array}{l}\text { Movements } \\
\text { slowness }\end{array}$ & Makhlouf et al. & 2018 & 15 & 74 & 20.27 & EPI \\
\hline PKN & $\begin{array}{l}\text { Baizabal-Carvallo } \\
\text { and Alonso-Juarez }\end{array}$ & 2021 & 2 & 125 & 1.60 & EPI/migraine \\
\hline
\end{tabular}

AKT - akathisia; DKN - dyskinesia; DTN - dystonia; EPI - epilepsy; MCL - myoclonus; MD - movement disorder; $\mathrm{N}$ - number of individuals in the study using VPA; NR - number of reports with the movement disorder; PKN parkinsonism; PSP - progressive supranuclear palsy; VPA - valproic acid/valproate 


\section{Table 5 - Clinical tools for the diagnosis of VPA-induced PKN}

1) History of VPA use

2) PKN after therapy with VPA use (at least two of the following symptoms: bradykinesia, rigidity, and postural instability)

3) Usually, symmetrical PKN with prominent action/postural over resting tremor

4) More commonly affects elderly individuals

5) Recovery with VPA withdrawal

6) Other possible causes of PKN excluded

PKN - parkinsonism; VPA - valproic acid/valproate

Pathophysiological mechanism

In the literature, we found five possible pathophysiological mechanisms to explains the VPA-induced PKN (Figure 6) (Brugger et al., 2016). First, the VPA can increase the concentration of GABA (Löscher, 2002), which inhibits the globus pallidus connections with the thalamus, decreasing activity of the direct pathway. Second, another effect of VPA is the inhibition of the histone deacetylase that may increase the expression of some genes and decrease others such as those involved in the synaptic transmission (Löscher, 2002), which was already suggested in cell studies. Third, most affected individuals were elderly, so they may already have an imbalance of dopaminergic and cholinergic activity, and when VPA is used, a decrease in dopamine occurs, favoring the indirect pathway (Sawle et al., 1990). Fourth, VPA can, in a normal concentration of neurotransmitters (balanced state), affect mitochondrial enzymes causing cellular energy deficiency, what increases the

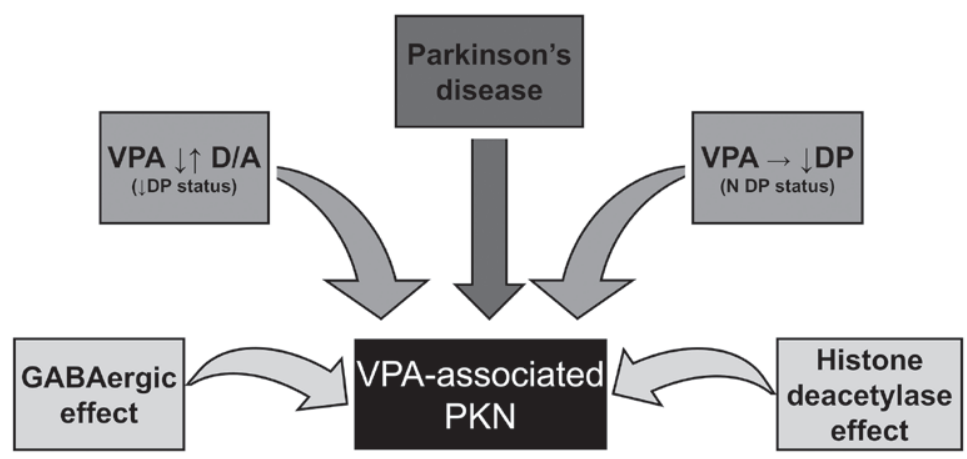

Figure 6 - Schematic diagram of the possible pathophysiological mechanisms to explains the valproate (VPA)-induced parkinsonism (PKN). The first pier represented by the GABAergic and histone deacetylase effects, which are directly related to the mechanism of action of valproate (VPA). The second pier is dependent on the dopamine (DP) status of the patient that could be decreased $(\downarrow)$ or normal $(N)$, in which the presence of VPA can causes a disbalance $(\downarrow \uparrow)$ of dopaminergic and cholinergic activity (D/A). The third pier is those individuals with coexisting Parkinson's disease. 
likelihood of an oxidative stress and consequently a neurodegenerative process, especially in the dopaminergic system (Löscher, 2002); a supporting fact for this theory is that individuals with particular mitochondrial lesions are more susceptible to the development of side effects related to VPA (Henry, 2003). Fifth, the diagnosis of Parkinson's disease in a significant percentage of the patients cannot be ruled out; as a result, perhaps the use of VPA was only by chance present in these individuals, who may develop uncorrelated Parkinson's disease.

\section{Management}

The most commonly reported management was the VPA discontinuation, adopted in more than seventy-five percent of the individuals. In some cases, dopamine precursors were attempted to manage and a partial improvement of the PKN symptoms was achieved; in the follow-up, levodopa showed to be effective and reduced the recovery time, but apparently these cases were after diagnosed with Parkinson's disease. One individual received bromocriptine, but no details were provided regarding treatment response. The VPA-induced PKN had the secondworst prognosis, full recovery was obtained in $77.02 \%$ of the subjects; about $10 \%$ of subjects only had partial improvement of the symptoms, with permanence of at least one symptom even after the last follow-up.

\section{Myoclonus (MCL)}

MCL was the first VPA-associated MD identified and was the second most commonly reported in the literature. The incidence of MCL related to VPA use found in the literature was $1.66-5.26 \%$ (Table 4). MCL-individuals were approximately twenty years younger than those affected by PKN, also, the VPA dose was lower, and MD onset and recovery happened sooner than in general data. The majority of the subjects involved were female (3:2). The presentation was asterixis and multifocal MCL. The MCL source was cortical and subcortical. It is worth mentioning that an important percentage of the cases only describe the neurological examination, giving the diagnosis without providing the findings of the electrodiagnostic studies. The management was drug withdrawal or the reduction of VPA-dose.

A feature reported in an important percentage of the patients, and possibly related to the mechanism of VPA-induced $\mathrm{MCL}$, is the high serum concentrations of ammonia, with no sign of liver failure described in the eight individuals assessed. Therefore, some authors believe that the explanation for $\mathrm{MCL}$ in the group of hyperammonemic individuals is the decrease of inhibitory neurotransmitters caused by ammonia, turning the individuals more susceptible to the development of MCL (Campostrini et al., 1983; Gastaut and Mege, 1985). On the other hand, the possibility that the ammonia levels found in these cases may be incidental cannot be excluded, as clinical trials with VPA already reported higher levels of this compound in individuals without any complaint (Löscher, 2002; Bowden, 2003). Also, this 
hypothesis can support the idea that perhaps VPA action on the central nervous system may lead to the development of MCL. Moreover, we hypothesized that the mechanism behind VPA-induced $M C L$ is probably related to VPA interaction with serotonin. In rat models, VPA caused both increase and decrease in serotonin concentration, depending on the site of action (Baf et al., 1994).

\section{Dystonia (DTN)}

In the DTN group, the data obtained for doses and times until onset and recovery from MD are comparable to general data on drug-induced DTN found in literature. Dick and Saunders (1980) probably described the first case of VPA-associated DTN. They reported the case of an individual with cervical and axial DTN that they attempted to treat with VPA, and the DTN-symptoms worsened.

The presentation in descending order of frequency was axial, cervical, oromandibular, blepharospasm, status dystonicus, and spasmodic dysphonia. We included the spasmodic dysphonia in the DTN group, but some authors believe that this disorder is a different entity, which goes beyond the aim of this review (Oh et al., 2004). In the same way, dropped head syndrome commonly reported with anticonvulsants may or may not be related to DTN (Werner et al., 2006). Possible interactions with clozapine, risperidone, quetiapine, and butamirate citrate were described.

One of the possible assumptions to explain the VPA-induced DTN is based on the GABAergic neurotransmission (Löscher, 2002). We believe that due to increased GABA levels by VPA the direct and indirect pathways that go to the thalamus might be interrupted. But the indirect pathway subactivity could probably predominate, and this disruption can increase the thalamocortical drive and eventually lead to DTN (Rissardo and Caprara, 2019). Another hypothesis related to dopaminergic activity in a mechanism similar to that proposed for the VPA-induced PKN can also be assumed (Brugger et al., 2016).

\section{Dyskinesia (DKN)}

Friis et al. (1983) reported in $53.33 \%$ of the individuals receiving VPA the development of DKN (Table 4). The presentation was orofacial, choreiform, hemichoreiform, and choreoathetotic. The association with another MD was observed with axial DTN and multifocal MCL. The DKN, stutter, and tics had the best prognosis with $100 \%$ recovery after the management.

The effects of VPA in the dopaminergic system probably explain the VPA-induced DKN. One fact that can support this hypothesis is the long time from starting VPA treatment until the MD onset, which was after 2.21 years. It is believed that due to the dopamine blockage, antipsychotics trigger inflammatory processes and the release of reactive oxygen species causing abnormal adaptations of the striatal organization, and ultimately leading to overactivation of the direct pathway (Lepping et al., 2011). 
The most frequent management was VPA withdrawal. Another option was the VPA-dose reduction in those individuals that a possible interaction related to protein intake or other medications was assumed. Moreover, Lancman et al. (1994) reported in one subject the substitution from VPA tablet to sprinkles improving the symptoms. A possible relation with the higher VPA plasma concentration and the DKN occurrence can be proposed in this case, since the sprinkles have their peak within four hours and other VPA formulation in one hour, especially the syrup (Cloyd et al., 1992).

Stutter, tic, and akathisia (AKT)

In our analysis, we included stutter because of the possible differential diagnosis of DTN, MCL, and even DKN due to poor description of the neurological examination. It was observed only in young adult males with bipolar disorder. The MD's times of onset and recovery were the shortest, and the VPA-dose was the lowest reported in relation to the general data. These features can support the assumption of possible DTN diagnosis. Also, the prognosis was excellent, with $100 \%$ recovery. The most effective treatment was the drug withdrawal. Mukherjee et al. (2015) attempted the VPA reintroduction, which caused the reappearance of the symptoms. Thus, in the VPA-induced stuttering, we believe that the rechallenge of VPA should not be done.

Tics were observed in three individuals and corresponded to less than one percent of VPA-induced MD reports. In the data extraction of the Zadikoff et al. (2007) study, the percentage of individuals developing tics with VPA use was $1.69 \%$. The patients presented with motor, motor and phonic, or only excessive eye blinking tics. Two cases reported had possible drug interactions, so a clear association can only be suspected. The drugs interacting with VPA were ziprasidone and lamotrigine; VPA can increase the levels of ziprasidone/lamotrigine by decreasing their metabolism (Alonso-Navarro et al., 2007; Thome-Souza et al., 2012). The VPA-dose decrease was enough for the achievement of a full recovery in the reports.

The less frequent MD published in the literature in association with VPA was AKT. But, it is noteworthy that this does not represent clinical practice. Friis et al. (1983) assessed 15 individuals using VPA, all of them developed some degree of AKT. Clos (2001) reported the case of a young adult female with bipolar disorder who was prescribed VPA 1,200 mg, and within one month she developed AKT-symptoms, but the diagnosis may be doubtful because the individual was in concomitant use of lithium.

\section{Conclusion}

In sum, VPA-associated MD was extensively reported in the literature probably due to availability, costs, and some historical factors of VPA. The most frequent and well described MD was PKN. In descending order of frequency, the following MD related 
to VPA were encountered: PKN $>$ MCL $>$ DTN $>$ DKN $>$ Stutter $>$ Tic $>$ AKT. Further studies are warranted to elucidate the occurrence of these MD associated with VPA and its underlying pathophysiology. Future reports need to clearly describe the clinical history of the patient considering a full investigation of other adverse events during their entire life as well as a long-term follow-up. We believe that the knowledge of VPA-associated MD raises the awareness about MD, and especially those drug-induced, which sometimes are challenging in the clinical practice to diagnose and manage.

\section{References}

Abreu, L. N., Issler, C., Lafer, B. (2009) Valproate-induced reversible pseudoatrophy of the brain and hyperammonemic encephalopathy in a bipolar patient. Aust. N. Z. J. Psychiatry 43(5), 484-485.

Aguglia, U., Gambardella, A., Zappia, M., Valentino, P., Quattrone, A. (1995) Negative myoclonus during valproate-related stupor. Neurophysiological evidence of a cortical non-epileptic origin. Electroencephalogr. Clin. Neurophysiol. 94(2), 103-108.

Aguilar, L. G., Ondo, W. G. (2008) Exploring the relationship between drug-induced parkinsonism and tardive dyskinesias. Mov. Disord. 23.

Alonso-Navarro, H., Adeva-Bartolomé, T., Jiménez-Jiménez, F. (2007) Tic disorders associated to epilepsy: 2 cases. Mov. Disord. 22, 283.

Alvarez-Gomez, M. J., Vaamonde, J., Narbona, J., Barao, M., Barona, P., Brannan, T., Gudin, M., Ibañez, R. (1993) Parkinsonian syndrome in childhood after sodium valproate administration. Clin. Neuropharmacol. 16(5), 451-455.

American Psychiatric Association (2013) Diagnostic and Statistical Manual of Mental Disorders (DSM- $5^{\circledR}$ ). American Psychiatric Association Publishing, Washington D.C.

Andrade, R., García-Espinosa, A., Pérez-Montoto, A., Toledo-Sotomayor, G., Remón-González, Y., FradesGarcía, V. (2010) Síntomas neuropsiquiátricos causados por ácido valproico. Rev. Neurol. 50(1), 62-63.

Armon, C., Shin, C., Miller, P., Carwile, S., Brown, E., Edinger, J. D., Paul, R. G. (1996) Reversible parkinsonism and cognitive impairment with chronic valproate use. Neurology 47(3), 626-635.

Athauda, D., Batley, R., Ellis, C. (2015) Clinically silent idiopathic Parkinson's disease unmasked by valproate use: a brief report. Aging Clin. Exp. Res. 27(3), 387-390.

Aukst-Margetić, B., Margetić, B. (2008) Stuttering as a side-effect of divalproex sodium. Psychiatry Clin. Neurosci. 62(6), 748-748.

Aykut, D. S., Aral, G., Tiryaki, A. (2018) Parkinsonism due to the use of long-term high-dose valproic acid in an elderly patient with mania syndrome: a case report and literature review. Psychiatry and Behavioral Sciences 8(4), 199-203.

Baf, M. M., Subhash, M., Lakshmana, K. M., Rao, B. S. R. (1994) Sodium valproate induced alterations in monoamine levels in different regions of the rat brain. Neurochem. Int. 24(1), 67-72.

Baizabal-Carvallo, J. F., Alonso-Juarez, M. (2021) Valproate-induced rest tremor and parkinsonism. Acta Neurol. Belg. 121, 515-519.

Barroso, B. (2002) Reversible parkinsonism induced by prolonged treatment with valproate. Therapie 57(4), 410-411. (in French)

Bayram, E., Karakaya, P., Topcu, Y., Yis, U., Hiz, S. (2013) Acute cervical dystonia after the first dose of butamirate citrate. Pediatr. Emerg. Care 29(1), 80-81.

Bennett, A., Rosen, J. (2019) Valproate-induced parkinsonism: A literature review and case series. American Psychiatric Association Annual Meeting. 
Bermudez, M., Gracia, D., Garcia, D., Cunha, E., Campos, F., Santistevan, T., Motta, G. (2017) Trismus secondary to valproate treatment in a woman with bipolar disorder: a case report. Archives of Clinical Psychiatry (Sao Paulo) 44(5), 137-137.

Bhattacharjee, S., Shankar, P. V., Elkider, M. (2016) Dopamine transporter single-photon emission computed tomography brain scan: A reliable way to distinguish between degenerative and drug-induced parkinsonism. Indian J. Nucl. Med. 31(3), 249-250.

Bhattacharjee, S., Chalissery, A. J., Barry, T., O’Sullivan, D., O’Connell, M., Lynch, T. (2017) Referral practice, reporting standards, and the impact of dopamine transporter scans done in a tertiary hospital. Neurol. India 65(6), 1264-1270.

Bodensteiner, J., Morris, H., Golden, G. (1981) Asterixis associated with sodium valproate. Neurology 31(2), 194-195.

Bondon-Guitton, E., Perez-Lloret, S., Bagheri, H., Brefel, C., Rascol, O., Montastruc, J.-L. (2011) Drug-induced parkinsonism: A review of 17 years' experience in a regional pharmacovigilance center in France. Mov. Disord. 26(12), 2226-2231.

Borroni, B., Rosati, A., Costanzi, C., Zulli, R., Mardighian, D., Gasparotti, R., Padovani, A. (2007) Multiple system atrophy due to prolonged valproic acid treatment. Int. Psychogeriatr. 19(4), 780-782.

Botturi, A., Silvani, A., Pravettoni, G., Paoli, R. A., Lucchiari, C. (2016) Reversible valproate induced Pisa syndrome and parkinsonism in a neuro-oncology patient with depression and epilepsy. Case Rep. Neurol. 8(2), 115-119.

Bowden, C. L. (2003) Valproate. Bipolar Disord. 5(3), 189-202.

Bowdle, T., Patel, I., Wilensky, A., Comfort, C. (1979) Hepatic failure from valproic acid. N. Engl. J. Med. 301(8), 435-436.

Brefel-Courbon, C., Gardette, V., Ory, F., Montastruc, J. L. (2006) Drug-induced myoclonus: A French pharmacovigilance database study. Neurophysiol. Clin. 36(5-6), 333-336.

Brugger, F., Bhatia, K. P., Besag, F. M. C. (2016) Valproate-associated parkinsonism: A critical review of the literature. CNS Drugs 30(6), 527-540.

Bruno, E., Holmes, P., Koutroumanidis, M. (2016) A complex hyperkinesia induced by valproate. Mov. Disord. Clin. Pract. 3(5), 513-514.

Campostrini, R., Paganini, M., Boncinelli, L., Zaccara, G., Arnetoli, G., Zappoli, R. (1983) Alterations of the state of consciousness induced by valproic acid: 6 case reports. Riv. Patol. Nerv. Ment. 104(1), 23-34. (in Italian)

Caruana Galizia, E., Isaacs, J. D., Cock, H. R. (2017) Non-hyperammonaemic valproate encephalopathy after 20 years of treatment. Epilepsy Behav. Case Rep. 8, 9-11.

ClinCalc (2020) The Top 300 of 2020. Available at: https://clincalc.com/DrugStats/Top300Drugs.aspx

Clos, F. H. (2001) Acute akathisia and sodium valproate. Int. J. Psychiatry Clin. Pract. 5(3), 219-222.

Cloyd, J. C., Kriel, R. L., Jones-Saete, C. M., Ong, B. Y., Jancik, J. T., Remmel, R. P. (1992) Comparison of sprinkle versus syrup formulations of valproate for bioavailability, tolerance, and preference. J. Pediatr. 120(4 Pt 1), 634-638.

Conforti, D., Borgherini, G., Fiorellini Bernardis, L. A., Magni, G. (1999) Extrapyramidal symptoms associated with the adjunct of nortriptyline to a venlafaxine-valproic acid combination. Int. Clin. Psychopharmacol. 14(3), 197-198.

Czarnecki, K., Kumar, N., Josephs, K. A. (2008) Parkinsonism and tardive antecollis in frontotemporal dementia - Increased sensitivity to newer antipsychotics? Eur. J. Neurol. 15(2), 199-201.

Dal, S., Whyte, S. (2019) 035 Valproate-induced parkinsonism “an early warning": case reports and review of literature. J. Neurol. Neurosurg. Psychiatry 90(e7), A12-A12.

Davoudi-Monfared, E., Radmehr, M., Ghaeli, P., Mousavi, M. (2019) A case series of severe hyperammonemia

Rissardo J. P.; Caprara A. L. F.; Durante Í. 
encephalopathy related to valproate: Can antipsychotics increase the risk? Iran. J. Psychiatry 14(3), 248-252.

De Dios, C., Fudio, S., Lorenzo, A. (2011) Reversible parkinsonism and cognitive decline due to a possible interaction of valproic acid and quetiapine. J. Clin. Pharm. Ther. 36(3), 430-432.

De Vries, E., Schoonvelde, M., Schumacher, G. (2018) No longer lost in translation: Evidence that Google Translate works for comparative bag-of-words text applications. Polit. Anal. 26(4), 417-430.

Dealberto, M.-J. C. C., Sarazin, F. F. A. (2008) Valproate-induced hyperammonemic encephalopathy without cognitive sequelae: A case report in the psychiatric setting. J. Neuropsychiatry Clin. Neurosci. 20(3), 369371.

del Real Francia, M. A., Sanz Martínez, J., Vaamonde Gamo, J., Gudín Rodríguez-Magariños, M., Ibáñez Alonso, R., Riñón, V. (1995) Parkinsonism induced by sodium valproate. Neurologia 10(9), 381-383. (in Spanish)

Dergalust, S., Ferrer, M., Cheng, E., Sayers, J. (2005) Drug-induced movement disorders caused by medications other than dopamine receptor blockers in the Veteran population. Mov. Disord. 20, 17-18.

Desai, D., Desai, S. (2015) Spectrum of disorders presenting as secondary Parkinsonism in a rural based medical teaching college in Western India. Mov. Disord. 30.

Dick, D., Saunders, M. (1980) Extrapyramidal syndrome with sodium valproate. Br. Med. J. 280(6208), 189.

Duggal, H. S. (2008) Acute Pisa syndrome and pharnygolaryngeal dystonia due to ziprasidone. J. Neuropsychiatry Clin. Neurosci. 20(1), 108-109.

Dunayevich, E., Strakowski, S. M. (1999) Olanzapine-induced tardive dystonia. Am. J. Psychiatry 156(10), 1662.

Easterford, K., Clough, P., Kellett, M., Fallon, K., Duncan, S. (2004) Reversible parkinsonism with normal betaCIT-SPECT in patients exposed to sodium valproate. Neurology 62(8), 1435-1437.

Evans, M. D., Shinar, R., Yaari, R. (2011) Reversible dementia and gait disturbance after prolonged use of valproic acid. Seizure 20(6), 509-511.

Fan, C. C., Huang, M. C., Liu, H. C. (2008) Lamotrigine might potentiate valproic acid-induced hyperammonemic encephalopathy. Prog. Neuropsychopharmacol. Biol. Psychiatry 32(7), 1747-1748.

Faridhosseini, F., Omidi-Kashani, F., Baradaran, A. (2015) Pisa syndrome associated with clozapine: A rare case report and literature review. Spine Deform. 3(4), 386-389.

Ferrari, A., De Merra, F., Filosto, M., Leonardi, A. (2004) Sodium valproate induced parkinsonism. Epilepsia 45, 132.

Foley, C., Slevin, J., Kasarskis, E. (2002) Divalproex-induced parkinsonism: A retrospective review of cases. Mov. Disord. 17, 250-251.

Friis, T., Christensen, T. R., Gerlach, J. (1983) Sodium valproate and biperiden in neuroleptic-induced akathisia, parkinsonism and hyperkinesia. A double-blind cross-over study with placebo. Acta Psychiatr. Scand. 67(3), 178-187.

Froomes, P. R., Stewart, M. R. (1994) A reversible parkinsonian syndrome and hepatotoxicity following addition of carbamazepine to sodium valproate. Aust. N. Z. J. Med. 24(4), 413-414.

Gara, L., Roberts, W. (2000) Adverse response to methylphenidate in combination with valproic acid. J. Child Adolesc. Psychopharmacol. 10(1), 39-43.

Gardner, T. M., Aziz, R., Muralee, S., Tampi, R. R. (2009) Valproic acid-induced myoclonus in a demented patient: a case report. Case Rep. Med. 2009, 392091.

Gastaut, J. L., Mege, J. L. (1985) Encephalopathy with asterixis induced by sodium valproate. Role of hyperammonemia without hepatic insufficiency. Presse Med. 14(7), 431. (in French)

Gaubert, M. L., Cougnaud, A., Ghali, A., Bruhat, C., Diquet, B., Berrut, G. (2006) Loss of autonomy related to valproic acid intake. J. Am. Geriatr. Soc. 54(12), 1971-1971.

Giordano, A., Amboni, M., Tessitore, A. (2014) Valproate-induced generalized choreoathetosis. Mov. Disord. Clin. Pract. 1(3), 271-272. 
Gosala Raja Kukkuta, S., Srinivas, M., Raghunandan, N., Thomas, M., Prabhu, A., Laly, M. (2013) Reversible vertical gaze palsy in sodium valproate toxicity. J. Neuroophthalmol. 33(2), 202-203.

Gunal, D. I., Guleryuz, M., Bingol, C. A. (2002) Reversible valproate-induced choreiform movements. Seizure 11(3), 205-206.

Gwinn, K. A., Caviness, J. N. (1997) Risperidone囚induced tardive dyskinesia and parkinsonism. Mov. Disord. 12(1), 119-121.

Habermeyer, B., Rabovsky, K., Jentzsch, C., Pinhard, K., Müller-Spahn, F. (2007) Cervical dystonia due to interaction of valproic acid and quetiapine. J. Clin. Psychopharmacol. 27(4), 396-397.

Hall, D. A., Ringel, S. P. (2004) Adult nonketotic hyperglycinemia (NKH) crisis presenting as severe chorea and encephalopathy. Mov. Disord. 19(4), 485-486.

Hassamal, S., Waller, S., Reese, K., Testa, C. (2016) Reversible valproic acid-induced parkinsonism and cognitive impairment in an elderly patient with bipolar disorder I. Turk Psikiyatri Derg. 27(3), 213-217. (in Turkish, English)

He, Z. F., Chen, J., Zhou, C. N., Rao, Z., Wang, X. H. (2017) Disabling tremor induced by long-term use of sodium valproate and lamotrigine: case report. Medicine $\mathbf{9 6 ( 4 7 ) , ~ e 8 7 1 1 . ~}$

Henry, T. R. (2003) The history of valproate in clinical neuroscience. Psychopharmacol. Bull. 37, 5-16 (Suppl. 2).

Hommet, C., Mondon, K., de Toffol, B., Constans, T. (2007) Reversible cognitive and neurological symptoms during valproic acid therapy. J. Am. Geriatr. Soc. 55(4), 628-628.

lijima, M. (2002) Valproate-induced parkinsonism in a demented elderly patient. J. Clin. Psychiatry 63(1), 75. Irons, R., Joanna, B., Apurba, C. (2015) The role of DaT scan in drug induced Parkinsonism. Mov. Disord. 30.

luppa, C. A., Diefenderfer, L. A. (2013) Risperidone-induced Pisa syndrome in MS: Resolution with lurasidone and recurrence with chlorpromazine. Ann. Pharmacother. 47(9), 1223-1228.

Jamora, D., Lim, S.-H., Pan, A., Tan, L., Tan, E.-K. (2007) Valproate-induced Parkinsonism in epilepsy patients. Mov. Disord. 22(1), 130-133.

Jankovic, J., Tolosa, E. (2007) Parkinson's Disease and Movement Disorders. Lippincott Williams and Wilkins, Baltimore.

Jopowicz, A., Kurkowska-Jastrzebska, I. (2014) Parkinsonian syndrome, a sporadic side effect of valproic acid. Pharmacother. Psychiatr. Neurol. 23(3-4), 199-205.

Kao, C.-D., Chen, W.-T., Chen, J., Yen, D.-J., Yiu, C.-H., Liao, K.-K. (2001) Valproate asterixis: a case report. Acta Neurol. Taiwan. 10(2), 123-126.

Khwaja, G. A., Ranjan, R., Gupta, M., Chowdhry, D., Hirve, M. (2010) Valproate-induced reversible “Parkinsonism Plus” syndrome. J. Indian Acad. Clin. Med. 11, 235-238.

Kim, H., Park, H., Sung, Y., Lee, H., Kim, D., Choi, S. (2018) Valproic acid related reversible parkinsonism. Asian Oceanian Congress of Neurology.

Kim, S. K., Oh, S. H., Kim, W. J. (2000) A case of valproate-induced reversible parkinsonism. J. Korean Neurol. Assoc. 18(5), 654.

Kiuru, S., livanainen, M. (1987) Camptocormia, a new side effect of sodium valproate. Epilepsy Res. 1(4), $254-257$.

Kohlhase, K., Knake, S., Timmermann, L., Rosenow, F., Strzelczyk, A. (2019) Akinetisch-rigide Bewegungsstörungen unter Antikonvulsiva. DGNeurologie 2(4), 287-291.

Lance, J., Anthony, M. (1977) Sodium valproate and clonazepam in the treatment of intractable epilepsy. Arch. Neurol. 34(1), 14-17.

Lancman, M. E., Asconapé, J. J., Penry, J. K. (1994) Choreiform movements associated with the use of valproate. Arch. Neurol. 51(7), 702-704.

Lapierre, O., Dubreucq, J. L., Beauchemin, M. A., Vinet, B. (1999) Valproic acid intoxication in a patient with bipolar disorder and chronic uremia. Can. J. Psychiatry 44(2), 188.

Rissardo J. P.; Caprara A. L. F.; Durante Í. 
Lautin, A., Stanley, M., Angrist, B., Gershon, S. (1979) Extrapyramidal syndrome with sodium valproate. Br. Med. J. 2(6197), 1035-1036.

Leclair-Visonneau, L., Rouaud, T., Debilly, B., Durif, F., Houeto, J.-L., Kreisler, A., Defebvre, L., Lamy, E., Volteau, C., Nguyen, J. M., Dily, S. L., Damier, P., Boutoleau-Bretonnière, C., Lejeune, P., Derkinderen, P. (2016) Randomized placebo-controlled trial of sodium valproate in progressive supranuclear palsy. Clin. Neurol. Neurosurg. 146, 35-39.

Lee, K. U. (2004) A case of reversible parkinsonism induced by valproate in a patient with bipolar disorder. Korean J. Psychopharmacol. 15(1), 107.

Lee, S., Koh, S., Park, K., Lee, D. (2007) Early dystonia in probable Creutzfeldt-Jakob disease with diffusion weighted MR images. Mov. Disord. 22, 117-118.

Lempérière, T. (2001) Brief history of the development of valproate in bipolar disorders. Encephale 27(4), 365-372. (in French)

Lepping, P., Delieu, J., Mellor, R., Williams, J. H. H., Hudson, P. R., Hunter-Lavin, C. (2011) Antipsychotic medication and oxidative cell stress: a systematic review. J. Clin. Psychiatry 72(3), 273-285.

Lindbom, U., Taubert, B., Fahlqvist, M. S., Bergens, A., Kimland, E., Jonsson, E. W., Bergman, U. (2009) Reversible dementia-like condition and parkinsonism in an elderly woman. Idiosyncratic adverse effects connected to 11 years of antiepileptic medication. Lakartidningen 106(12), 863-865. (in Swedish)

Löscher, W. (2002) Basic pharmacology of valproate. CNS Drugs 16(10), 669-694.

Louter, M., Tromp, S. C. (2009) Parkinsonism due to the medication. Ned. Tijdschr. Geneeskd. 153, A336-A336. (in Dutch)

Lyell, V., Henderson, E., Ahearn, D., MacMahon, D. (2010) Multi-centre survey of new patients referred from primary care with parkinsonism what proportion are on medications which can cause drug induced parkinsonism? Mov. Disord. 25(7), 224.

Macphee, G. (2005) Valproate induced parkinsonism. J. R. Coll. Physicians Edinb. 35(3), 214.

Macphee, G. J. A., Stewart, D. A. (2007) Diagnosis of Parkinsonism in older patients receiving sodium valproate. Mov. Disord. 22(8), 1211-1211.

Mahmoud, F., Tampi, R. R. (2011) Valproic acid-induced parkinsonism in the elderly: A comprehensive review of the literature. Am. J. Geriatr. Pharmacother. 9(6), 405-412.

Makhlouf, S., Mansour, M., Msselmeni, M., Bedoui, I., Zaouali, J. (2018) Side effects of sodium valproate in a Tunisian population. Res. J. Nerv. Syst. 1(1), 8.

Mangewala, V., Sarwar, S., Rosenberger, R., Rais, T., Knox, M. (2013) Valproate-induced hyperammonemic encephalopathy: a case report. Innov. Clin. Neurosci. 10(5-6), 12-13.

Masmoudi, K., Gras-Champel, V., Bonnet, I., Pannier, M., Masson, H., Rosa, A., Andrejak, M. (2000) Dementia and extrapyramidal problems caused by long-term valproic acid. Therapie 55(5), 629-634.

Masmoudi, K., Gras-Champel, V., Masson, H., Andréjak, M. (2006) Parkinsonism and/or cognitive impairment with valproic acid therapy: a report of ten cases. Pharmacopsychiatry 39(1), 9-12.

Maximov, K., Maximov, G. (2008) Valproate-induced parkinsonism in epilepsy patient - A case report. Acta Medica Bulgarica XXXV(1/2008), 38-42.

Morrison, P. F., Sankar, R., Shields, W. D. (2006) Valproate-induced chorea and encephalopathy in atypical nonketotic hyperglycinemia. Pediatr. Neurol. 35(5), 356-358.

Mukherjee, S., Sen, S., Chatterjee, S. S., Biswas, A., Tripathi, S. K. (2015) Divalproex-induced stuttering: A rare case report. Eur. J. Psychol. Educ. Studies 2(1), 25.

Munhoz, R. P., Werneck, L. C., Teive, H. A. G. (2010) The differential diagnoses of parkinsonism: Findings from a cohort of 1528 patients and a 10 years comparison in tertiary movement disorders clinics. Clin. Neurol. Neurosurg. 112(5), 431-435. 
Naranjo, C. A., Busto, U., Sellers, E. M., Sandor, P., Ruiz, I., Roberts, E. A., Janecek, E., Domecq, C., Greenblatt, D. J. (1981) A method for estimating the probability of adverse drug reactions. Clin. Pharmacol. Ther. 30(2), 239-245.

Nayak, R., Pandurangi, A., Bhogale, G., Patil, N., Chate, S. (2012) Asterixis (flapping tremors) as an outcome of complex psychotropic drug interaction. J. Neuropsychiatry Clin. Neurosci. 24(1), E26-E27.

Nouzeilles, M., García, M., Rabinowicz, A., Merello, M. (1999) Prospective evaluation of parkinsonism and tremor in patients treated with valproate. Parkinsonism Relat. Disord. 5(1-2), 67-68.

Nutt, J., Williams, A., Plotkin, C., Eng, N., Ziegler, M., Calne, D. (1979) Treatment of Parkinson's disease with sodium valproate: Clinical, pharmacological, and biochemical observations. Can. J. Neurol. Sci. 6(3), 337-343.

Oh, J., Park, K. D., Cho, H. J., Choi, K. G., Jung, S. M. (2004) Spasmodic dysphonia induced by valproic acid. Epilepsia 45(7), 880-881.

Onofrj, M., Thomas, A., Paci, C. (1998) Reversible parkinsonism induced by prolonged treatment with valproate. J. Neurol. 245(12), 794-796.

Pal, G., Lin, M. M., Laureno, R. (2014) Asterixis: A study of 103 patients. Metab. Brain Dis. 29(3), 813-824.

Park-Matsumoto, Y. C., Tazawa, T. (1998) Valproate induced parkinsonism. No To Shinkei 50(1), 81-84.

Patel, S. R., Patel, K. P., Gupta, S. D., Malhotra, S. D., Patel, P. R. (2018) Valproate induced Parkinsonism. Natl. J. Integr. Res. Med. 9(6), 72-74.

Penot, J.-P., Pradeau, F. (2010) Syndrome démentiel et extrapyramidal iatrogène: Effet secondaire rare de l'association acide valproïque-aspirine. Presse Med. 39(2), 279-280.

Power, C., Blume, W., Young, G. (1990) Reversible parkinsonism associated with valproate therapy. Neurology 40, 139 (Suppl. 1).

Prakash, S., Harbo, T., Christensen, J. (2015) Valproate can induce reversible encephalopathy. Ugeskr. Laeger 177(20), 945-946 (in Danish).

Raja, M., Azzoni, A. (2002) Valproate and quetiapine overdose with benign outcome: a case report. Int. J. Psychiatry Clin. Pract. 6(3), 173-174.

Randhawa, J., Mehanna, R. (2019) Drug-induced parkinsonism may persist beyond two years after discontinuation of dopamine transmission blocking agents. Mov. Disord. 34, 599.

Reif, A., Hamelbeck, B., Pfuhlmann, B. (2003) Acute akinetic crisis with marked cognitive impairment due to valproate treatment. Int. J. Geriatr. Psychiatry 18(4), 356-357.

Reif, A., Leonhard, C., Mössner, R., Lesch, K.-P., Fallgatter, A. J. (2004) Encephalopathy and myoclonus triggered by valproic acid. Prog. Neuropsychopharmacol. Biol. Psychiatry 28(6), 1061-1063.

Ricard, C., Martin, K., Tournier, M., Bégaud, B., Verdoux, H. (2005) A case of Parkinsonian syndrome, cognitive impairment and hyperammonemia induced by divalproate sodium prescribed for bipolar disorder. Encephale 31(1), 98-101. (in French)

Rissardo, J. P., Caprara, A. L. F. (2019) Comment: Dystonia and asterixis in acute thalamic infarct: Proposed mechanism. Ann. Mov. Disord. 2(3), 138-139.

Rissardo, J. P., Caprara, A. L. F., Silveira, J. O. F. (2019) Valproic acid-associated pancytopenia: A dosedependent adverse effect. Rom. J. Neurol. 18(3), 150-153.

Ristić, A. J., Vojvodić, N., Janković, S., Sindelić, A., Sokić, D. (2006) The frequency of reversible parkinsonism and cognitive decline associated with valproate treatment: A study of 364 patients with different types of epilepsy. Epilepsia 47(12), 2183-2185.

Rottach, K. G., Weiss-Brummer, J., Wieland, U., Schmauß, M. (2000) Valproinsäure als Phasenprophylaktikum Ein Fall von Valproat-Enzephalopathie. Nervenarzt 71(5), 401-403.

Salazar, Z., Tschopp, L., Calandra, C., Micheli, F. (2008) Pisa syndrome and parkinsonism secondary to valproic acid in Huntington's disease. Mov. Disord. 23(16), 2430-2431.

Rissardo J. P.; Caprara A. L. F.; Durante Í. 
Sarna, J., Pringsheim, T. (2011) Progressive supranuclear palsy-like phenotype associated with concomitant exposure to mood stabilizer and neuroleptic. Mov. Disord. 26.

Sasso, E., Delsoldato, S., Negrotti, A., Mancia, D. (1994) Reversible valproate-induced extrapyramidal disorders. Epilepsia 35(2), 391-393.

Sawle, G., Colebatch, J., Shah, A., Brooks, D., Marsden, C., Frackowiak, R. (1990) Striatal function in normal aging: Implications for Parkinson's disease. Ann. Neurol. 28(6), 799-804.

Schreur, L., Middeljans-Tijssen, C. W., Hengstman, G. J. D., Olde Rikkert, M. G. M. (2009) Cognitieve stoornissen en parkinsonisme bij gebruik van valproïnezuur. Tijdschr. Gerontol. Geriatr. 40(1), 29-33.

Sechi, G. P., Conti, M., Sau, G. F., Cocco, G. A. (2008) Valproate-induced parkinsonism, glial cells and Alexander's disease. Prog. Neuropsychopharmacol. Biol. Psychiatry 32(5), 1351-1352.

Shill, H. A., Fife, T. D. (2000) Valproic acid toxicity mimicking multiple system atrophy. Neurology 55(12), 1936-1937.

Shirasaka, Y., Mitsuyoshi, I. (1999) A case of epileptic negative myoclonus: Therapeutic considerations. Brain Dev. 21(3), 209-212.

Silver, M., Factor, S. A. (2013) Valproic acid-induced parkinsonism: Levodopa responsiveness with dyskinesia. Parkinsonism Relat. Disord. 19(8), 758-760.

Simões, R., Inácio, N., Silva, V., Arraiolos, A., Alegria, P., Canas, N., Vale, J. (2016) Valproate-induced reversible parkinsonism - A case series. Mov. Disord. 31.

Sleegers, M. J. M., Beutler, J. J., Hardon, W. J., Berden, J. H. M., Verhave, J. C., Conemans, J. M. H., Hollander, D. A., Dautzenberg, P. L., Hoogeveen, E. K. (2010) Reversible rapidly progressive dementia with parkinsonism induced by valproate in a patient with systemic lupus erythematosus. J. Am. Geriatr. Soc. 58(4), 799-801.

Srinivasan, S., Lok, A. W. (2010) Valproate-induced reversible hemichorea. Mov. Disord. 25, 1511-1512.

Surendran, I., Sahoo, S., Gupta, G., Chauhan, N., Grover, S. (2016) Valproate-induced hyperammonemic encephalopathy in an elderly patient with bipolar disorder. J. Geriatr. Ment. Health 3(2), 172-175.

Tada, H., Ogihara, T., Nakamura, T., Sasayama, D., Sugiyama, N., Takahashi, Y., Washizuka, S., Amano, N. (2017) A case of severe parkinsonism in an elderly person induced by valproic acid. Psychogeriatrics 17(1), 76-77.

Teive, H. A. G., Souza, M., Antoniuk, S., Barbosa, E., Scaff, M., Werneck, L. (2004a) Status dystonicus: Report of four cases. Mov. Disord. 19, 114.

Teive, H. A. G., Troiano, A. R., Germiniani, F. M. B., Werneck, L. C. (2004b) Flunarizine and cinnarizineinduced parkinsonism: A historical and clinical analysis. Parkinsonism Relat. Disord. 10(4), 243-245.

Thome-Souza, S., Moreira, B., Valente, K. D. (2012) Late adverse effects of the coadministration of valproate and lamotrigine. Pediatr. Neurol. 47(1), 47-50.

Thygesen, K. S., Wolf, P. (2005) Valproate-caused encephalopathy. Ugeskr. Laeger 167(40), 3793-3794. (in Danish)

Toribio-Díaz, M. E., Morera-Guitart, J., Palao-Duarte, S. (2008) Reversible parkinsonism and cognitive impairment following treatment with valproate. Rev. Neurol. 47(7), 390-391. (in Spanish)

van de Velde, K., Cras, P., Helsen, G. (2011) Acute chorea caused by valproate in an elderly. Acta Neurol. Belg. 111(3), 220-221.

van der Zwan, A. Jr. (1989) Transient Parkinson syndrome and tremor caused by the use of sodium valproate. Ned. Tijdschr. Geneeskd. 133(24), 1230-1232. (in Dutch)

Vogt, H., Mothersill, I. (2000) Asterixis: An adverse event also with new anti-epileptic drugs. Epilepsia 41, 226 (Suppl. 7).

Wang, Y., Xia, J., Helfer, B., Li, C., Leucht, S. (2016) Valproate for schizophrenia. Cochrane Database Syst. Rev. 11(11), CD004028. 
180) Prague Medical Report / Vol. 122 (2021) No. 3, p. 140-180

Werner, I., Bruchert, S., Meyer, K., Bohhalter, S. (2006) Dropped head syndrome in long-term care patients with chronic epilepsy and mental retardation-relationship to antiepileptic treatment. Mov. Disord. 21, 373.

Wils, V., Golüke-Willemse, G. (1997) Extrapyramidal syndrome due to valproate administration as an adjunct to lithium in an elderly manic patient. Int. J. Geriatr. Psychiatry 12(2), 272.

Yilmaz, A. E., Donmez, A., Orun, E., Tas, T., Isik, B., Sonmez, F. M. (2013) Methylphenidate-induced acute orofacial and extremity dyskinesia. J. Child Neurol. 28(6), 781-783.

Yohanan, M., Aulakh, J. S., Weith, J., Hawkins, J. W. (2006) Pisa syndrome in a patient in a wheelchair taking valproic acid. Am. J. Psychiatry 163(2), 325-326.

Yomtoob, J., Koloms, K., Bega, D. (2018) DAT-SPECT imaging in cases of drug-induced parkinsonism in a specialty movement disorders practice. Parkinsonism Relat. Disord. 53, 37-41.

Yoon, J. H., Lee, P. H., Yong, S. W., Park, H. Y., Lim, T. S., Choi, J. Y. (2008) Movement disorders at a university hospital emergency room. An analysis of clinical pattern and etiology. J. Neurol. 255(5), 745749.

Zaccara, G., Paganini, M., Campostrini, R., Arnetoli, G., Zappoli, R., Moroni, F. (1984) Hyperammonemia and valproate-induced alterations of the state of consciousness. A report of 8 cases. Eur. Neurol. 23(2), 104-112.

Zadikoff, C., Munhoz, R. P., Asante, A. N., Politzer, N., Wennberg, R., Carlen, P., Lang, A. (2007) Movement disorders in patients taking anticonvulsants. J. Neurol. Neurosurg. Psychiatry 78(2), 147-151.

Rissardo J. P.; Caprara A. L. F.; Durante Í. 